Document downloaded from:

http://hdl.handle.net/10251/103996

This paper must be cited as:

Pastor, JV.; García-Oliver, JM.; García Martínez, A.; Pinotti, M. (2017). Effect of laser induced plasma ignition timing and location on Diesel spray combustion. Energy Conversion and Management. 133:41-55. doi:10.1016/j.enconman.2016.11.054

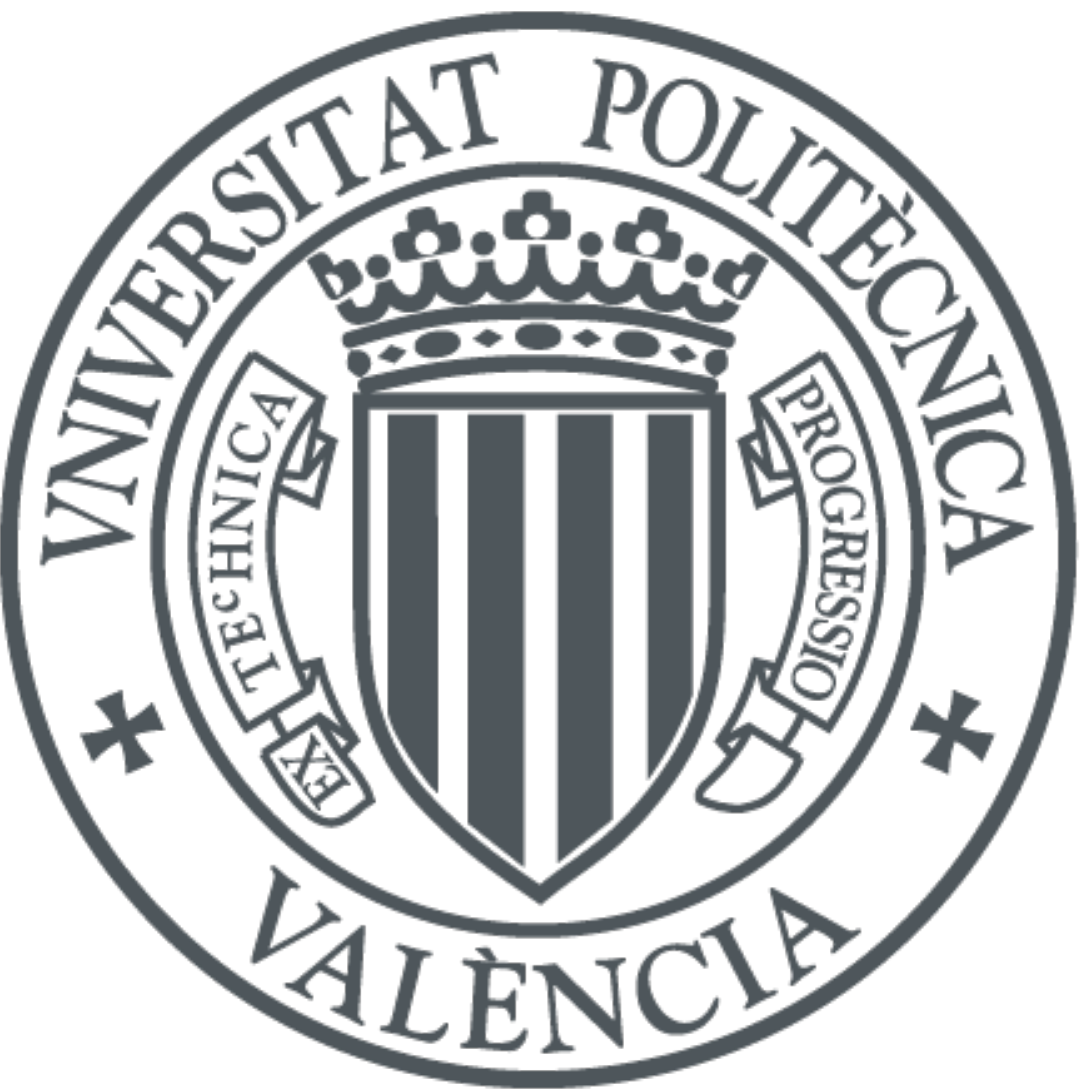

The final publication is available at

http://dx.doi.org/10.1016/j.enconman.2016.11.054

Copyright Elsevier

Additional Information 


\section{Effect of Laser Induced Plasma Ignition Timing and Location on Diesel \\ Spray Combustion}

\section{Authors}

José V. Pastor, José M. García-Oliver, Antonio García, Mattia Pinotti

\section{Affiliation}

CMT Motores Térmicos - Universitat Politècnica de València, Camino de Vera s/n, 46022, Valencia, Spain.

\section{Corresponding Author}

Dr. José V. Pastor

CMT - Motores Térmicos /Universitat Politècnica de València

jpastor@mot.upv.es

HIGHLIGHTS

Laser Plasma Ignition is applied to a direct injection Diesel spray, compared with auto-ignition.

Critical local fuel/air ratio for LIP provoked ignition is obtained.

The LIP system is able to stabilize Diesel combustion compared to auto-ignition cases

Varying LIP position along spray axis directly affects Ignition-delay.

Premixed combustion is reduced both by varying position and delay of the LIP ignition system. 


\section{KEYWORDS}

Laser Plasma Ignition, Diesel Spray combustion, Diesel Spray provoked ignition, Diesel combustion analysis, Combustion visualization, Diesel Spray modeling.

\section{ABSTRACT}

An experimental study about the influence of the local conditions at the ignition location on combustion development of a direct injection spray is carried out in an optical engine. A laser induced plasma ignition system has been used to force the spray ignition, allowing comparison of combustion's evolution and stability with the case of conventional autoignition on the Diesel fuel in terms of ignition delay, rate of heat release, spray penetration and soot location evolution. The local equivalence ratio variation along the spray axis during the injection process was determined with a 1D spray model, previously calibrated and validated. Upper equivalence ratios limits for the ignition event of a direct injected Diesel spray, both in terms of ignition success possibilities and stability of the phenomena, could been determined thanks to application of the laser plasma ignition system. In all laser plasma induced ignition cases, heat release was found to be higher than for the autoignition reference cases, and it was found to be linked to a decrease of ignition delay, with the premixed peak in the rate of heat release curve progressively disappearing as the ignition delay time gets shorter. Ignition delay has been analyzed as a function of the laser position, too. It was found that ignition delay increases for plasma positions closer to the nozzle, indicating that the amount of energy introduced by the laser induced plasma is not the only parameter affecting combustion initiation, but local equivalence ratio plays a major role, too. 


\section{NOMENCLATURE}

\begin{tabular}{|c|c|}
\hline ARoHR & Apparent Rate of Heat Release \\
\hline ASOE & After Start of Energizing \\
\hline$B T D C$ & Before Top Dead Center \\
\hline$C A D$ & Crank Angle Degree \\
\hline $\mathrm{Cl}$ & Compression Ignition \\
\hline CMOS & Complementary metal-oxyde-semiconductor \\
\hline DI & Direct Injection \\
\hline LIP & Laser Inducted Plasma Ignition \\
\hline Nd:YAG & Neodymium-doped yttrium aluminium garnet \\
\hline RoHR & Rate of Heat Release \\
\hline$S$ & Spray Vapor Penetration \\
\hline SIDI & Spark Ignited Direct Ignition \\
\hline SOE & Start of Energizing \\
\hline sol & Start of Injection \\
\hline$T D C$ & Top Dead Center \\
\hline UV & Ultraviolet \\
\hline$X e$ & Xenon \\
\hline
\end{tabular}




\section{INTRODUCTION}

Internal combustion engines play a fundamental role in society nowadays as the main powertrain for transportation and energy production purposes and consequently is one of the principal sources of pollutant emissions. For this reason, even a slight improvement in its combustion control will represent a considerable impact on the reduction of overall emissions to the environment.

The two most common engines for automobiles, the Otto and Diesel ones have evolved along time at different speeds to make use of efficient direct injection (DI) of the fuel in the combustion chamber. Thus, whilst DI Diesel engines are the nearly unique common Diesel engine in the market for more than two decades, the SIDI engines are spreading in the market only very recently [1]. This development is linked to the innovative research on the physics of the injection, evaporation fuel mixing and combustion of direct injection sprays in the cylinder and how the different stages of the combustion process are affected by the combustion chamber thermodynamic conditions and injection settings. In particular, it is now well known how the complex phenomenon of the ignition strongly affects the subsequent combustion development [2] and the correlated emissions [3], which is in the basis of some of the new combustion modes [4] [5]. Especially the early stages of the ignition phenomena and the local equivalence ratio of the mixture at the ignition timing have shown to affect the successive flame structure and development, leading to substantial difference in the pollutant production and overall efficiency of the combustion process [6].

Despite the continuous improvement in both Otto and Diesel engines along the years, the ignition source of the Otto engine has changed very little in almost 100 years of development, remaining still referred to a spark ignition generated by an electrical system. An electrical spark plug ignition consists essentially of the generation of plasma through an electrical breakthrough that occurs between two electrodes when high voltage is applied. In the last twenty years, some valid 
alternatives to the electrical discharge for the generation of a plasma spark [6] has been investigated by several authors [7]. Considering results of early studies on laser induced ionization and breakdown of gases [8] [9], the technological advance reached by the modern laser systems has permitted the progress of studies for the development of a laser plasma spark ignition. Q-switched lasers can deliver short-pulse and high intensity radiation emissions from the UV to the nearinfrared spectral region and are well known for their ability of generating a so called non-resonant breakdown in different gaseous media [10]. Focusing the beam below a certain diameter value, which depends on the laser emission power and beam quality, the specific gas local energy density threshold for the breakdown can be overcome in the focal region. This threshold limit does not only depend on the media, but, as it was shown experimentally [11] and theoretically [12] it seems to be inversely dependent on local pressure too. This pressure dependence is particularly favorable for engine applications, where the combustion chamber high pressure permits to reach the breakdown event with lower energy density concentration [13]. Weinberg et al. [14] first reported the ability of such laser induced plasmas of igniting combustible mixtures, and Dale et al. [15] demonstrated successful operation of a laser-ignited internal combustion engine, also at mixtures leaner than those with the conventional electrical spark plug. In the last few years, with the request for SI modern engines to operate under much higher compression ratios, faster compression rates and leaner fuel-to-air ratios [16], a renewed interest has raised around this ignition technique [17]. Several authors have shown interest in the potential of such ignition technique also applied to direct injected sprays for new $\mathrm{Cl}$ combustion modes [18] and, moreover, the new freedom allowed by its application [19], considering the study of the combustion phenomena [20], makes it also a very interesting tool for internal combustion engine research purposes. Moreover, such ignition system could provide wide new possibilities to new combustion modes engine, such as $\mathrm{PCCl}$ engines, 
especially in terms of dual fueling application, as external control on a dual-fuel single injection system engines.

This considered, the here reported work presents an experimental study to extend the understanding of the combustion behavior as a function of the local conditions at the ignition site. For this purpose, a laser inducted plasma ignition technique was used to reach the level of freedom desired in the selection of temporal and spatial location of the ignition point in a Diesel spray. In this way different local conditions of the fuel at the ignition location were tested, to study how the local mixture equivalence ratio affects the ignition and combustion characteristics of a direct injection spray, in comparison to the typical autoignition of conventional Diesel combustion. Moreover, the application of the LIP technique to such conditions on Diesel spray has allowed to determine practical limits of the system capabilities to ignite such kind of direct injected spray, and control the combustion, carrying out a direct comparison with the auto-ignition baseline reference case. For the correct results interpretations of the experimental study, the reliability of the laser optical system in the plasma generation was of primary importance for the consideration respect eventual misfire registered event. A preliminary study on the effectiveness of the optical system in the breakdown generation was also realized [21].

\section{EXPERIMENTAL SETUP}

In the present section, a description on the test facility including the different systems employed for the study is made. Experiments were conducted in an optical test rig equipped with optical accesses that made it possible for the laser beam to be focused in the combustion chamber to induce plasma on the spray axis. 


\subsection{Experimental Facility}

\subsubsection{Optical Test Rig}

The optical test rig is a modified port scavenging two-stroke single cylinder direct injection Diesel engine (Jenbach JW50), with three-liter displacement, 15.8:1 compression ratio and motored at the low engine speed of $500 \mathrm{rpm}$. Intake and exhaust are managed by transfers on the liner and the cylinder head was adapted to offer various optical access to the combustion chamber [22] [23]. The cylinder head and engine temperatures are both controlled via coolant recirculation. A cylindrical combustion chamber was designed specifically to avoid spray wall impingement and presents, as showed in Figure 1, an upper port where the injector is mounted. In this work, a Bosch common rail injector was used with a cylindrical single-hole of 140 um that was previously characterized geometrically and hydraulically. Standard European Diesel fuel was used in all the experiments. The combustion chamber is also provided with 4 large orthogonal access, one of which is used for mounting a pressure transducer to record the in-chamber pressure during tests, both for system control and data acquisition. The other three entrances are equipped with oval shaped fused silica windows of $30 \times 81 \times 28 \mathrm{~mm}$, which guarantees an optimal optical access to the chamber permitting the visualization of nearly the entire spray or flame length and the focusing of the laser beam inside the chamber. 


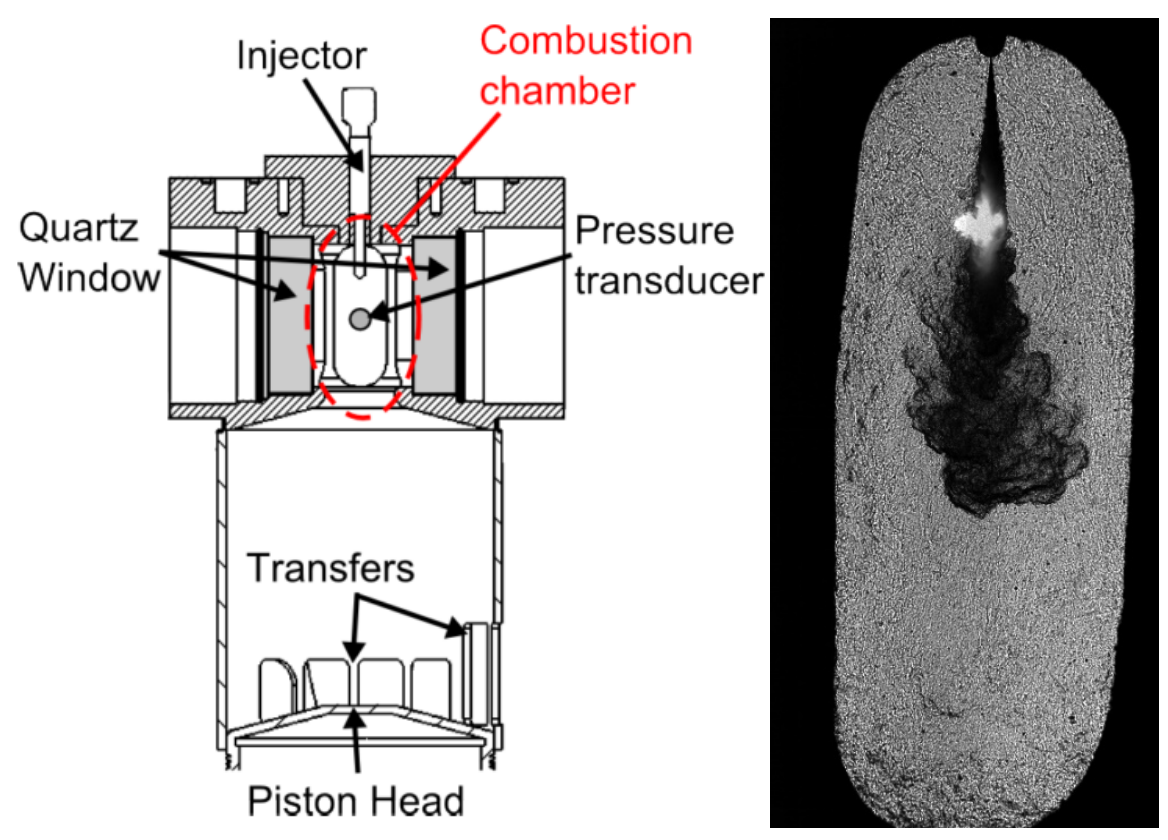

Figure 1 - Left - Scheme of the optical test rig engine's head adapted to allocate optical access. The position of the injector, pressure transducer and fused silica quartz window can be observed. Right - Example of the field of view of the internal of the combustion chamber, taken with Schlieren visualization. The direct injection spray vapor phase and the plasma spark inducted with the LIP system can be observed.

The test rig permits independent regulation on in-cylinder temperature, pressure and gas composition, which makes it possible to replicate a wide range of thermodynamic conditions as in current passenger car engines. In order to keep in-cylinder conditions constant, the engine is operated under skip-fired mode, so that an injection takes place each 30 cycles. This guarantees that in-cylinder conditions are not influenced by residual gases from the previous cycle and minimizes the effect of engine thermal transients.

\subsubsection{Laser Plasma Induction System}

The plasma was induced using a $10 \mathrm{~Hz}$ flashlamp pumped Nd:YAG Laser (Continuum Surelite II model) operated at a pulse energy lower than $350 \mathrm{~mJ}$ at $1064 \mathrm{~nm}$. The beam focusing in the combustion chamber was performed with an nBK-7 lens of $300 \mathrm{~mm}$ focal length. The whole system was designed to allow the free positioning of the focal point of the focusing lens into the combustion 
chamber, in order to control de plasma induction location with respect to the theoretical volume occupied by the spray during the injection. For this reason, the vertical and horizontal position of the focusing lens was controlled by moving two perpendicular platforms. More details regarding the optical setup for plasma generation as well as a study of its repeatability and its reliability characterization are detailed in a previous work [21]. A schematic representation of the system could be seen in Figure 2.

\subsection{Measurement Tools}

\subsubsection{Spray and flame visualization}

A single optical setup was used for the plasma and spray combustion visualization by applying two different optical techniques, namely Schlieren visualization and Natural Luminosity imaging. A diagram of the arrangement is shown in Figure 2.

For Schlieren analysis a collimated light beam was used for the generation of the Schlieren effect by focusing the light source (300W Xe continuous lamp, Karl Storz Xenon Nova 300) with a liquid fiber through a pin hole of $0.15 \mathrm{~mm}$, to form a light spot at the focal point of a $150 \mathrm{~mm}$ diameter spherical mirror with a focal length of $610 \mathrm{~mm}$. The mirror collimates the beam that then enters the combustion chamber reflected through another redirecting mirror. 


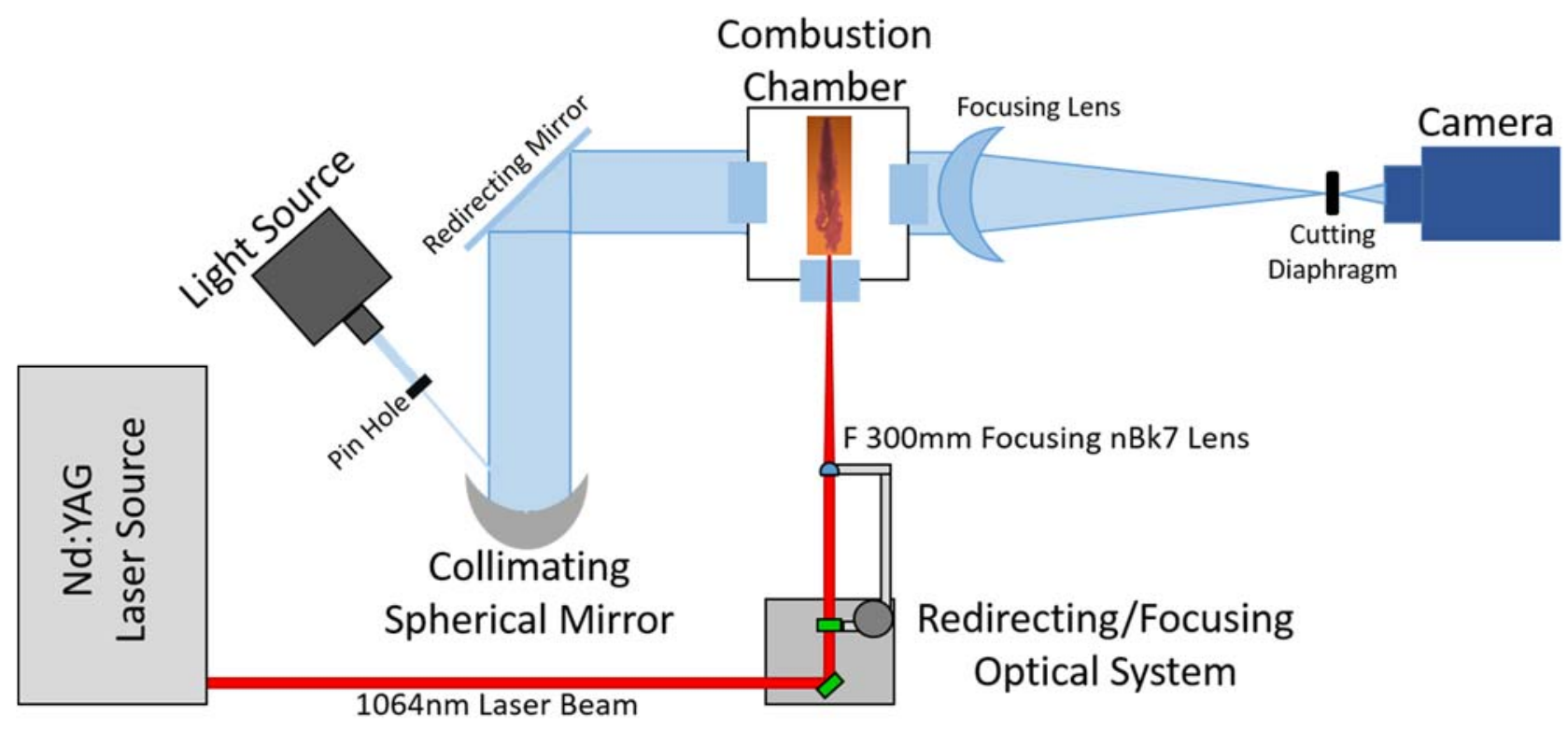

Figure 2 - Schematic representation of the optical system used for the Schlieren imaging acquisition and for the Laser plasma induction.

On the other side of the combustion chamber light was collected by a $150 \mathrm{~mm}$ diameter lens with a focal length of $450 \mathrm{~mm}$, sufficient to guarantee a minimal light dispersion. A cutting diaphragm was positioned at the camera lens focal length to apply a spatial filtering to the focalized beam in the Fourier's plane. Both the light source and the cutoff diaphragm were only used in Schlieren visualization tests, the latter one being replaced by a neutral density filter when carrying out broadband radiation imaging. Images where taken with a high-speed CMOS camera (Phantom V12.0) equipped with a $100 \mathrm{~mm}$ f:2 camera lens (Zeiss Makro-Planar $\mathrm{T}^{*}$ 2) to collect all the light into the camera sensor, allowing a very sharp definition of the focusing zone.

The aim of this technique is to register images of spray combustion, particularly focusing on the determination of the spray penetration in the combustion chamber. Spray auto-ignition and provoked ignition cases were registered with the high speed CMOS camera synchronized with the injection signal while the combustion chamber was continuously illuminated with the collimated beam. 
The same setup was used to register the high intensity broadband radiation produced by the incandescence of the soot particles in the flame. In this case the light source was kept off, a neutral density filter was set before the camera lens to limit the soot emission radiation and camera shutter was slightly increased. The camera acquisition parameters used with both techniques are listed in Table 1.

\begin{tabular}{ll}
\hline \multicolumn{2}{c}{ Phantom V12.0 CMOS Camera Acquisition set-up } \\
\hline Image resolution & 384 x $800 \mathrm{pix}$ \\
Pixel/mm ratio & $10.28 \mathrm{pix} / \mathrm{mm}$ \\
Acquisition Framerate & $16000 \mathrm{fps}$ \\
Image-Image Interval & $62.5 \mu \mathrm{s}$ \\
Exposure time (Schlieren Imaging) & $6 \mu \mathrm{s}$ \\
Exposure time (Natural Luminosity) & $8 \mu \mathrm{s}$
\end{tabular}

Table 1 - Fast CMOS camera settings used for the images acquisition for the two different imaging techniques

\subsubsection{Pressure Signal Processing}

Thermodynamic conditions evolution during compression have been calculated following the standard procedure described in [24], from the cylinder pressure using a first-law thermodynamic analysis considering blow-by, heat transfer and mechanical deformations. The instantaneous incylinder pressure evolution registered during the combustion tests was principally used for the quantification of the spray ignition delay, in order to determine if the laser plasma ignition system was effectively provoking an earlier ignition of the Diesel spray before the natural auto-ignition event. An AVL GU13P pressure transducer coupled to a Kistler 5011 charge amplifier is used to measure the cylinder pressure with a sampling frequency of $100 \mathrm{kHz}$. 

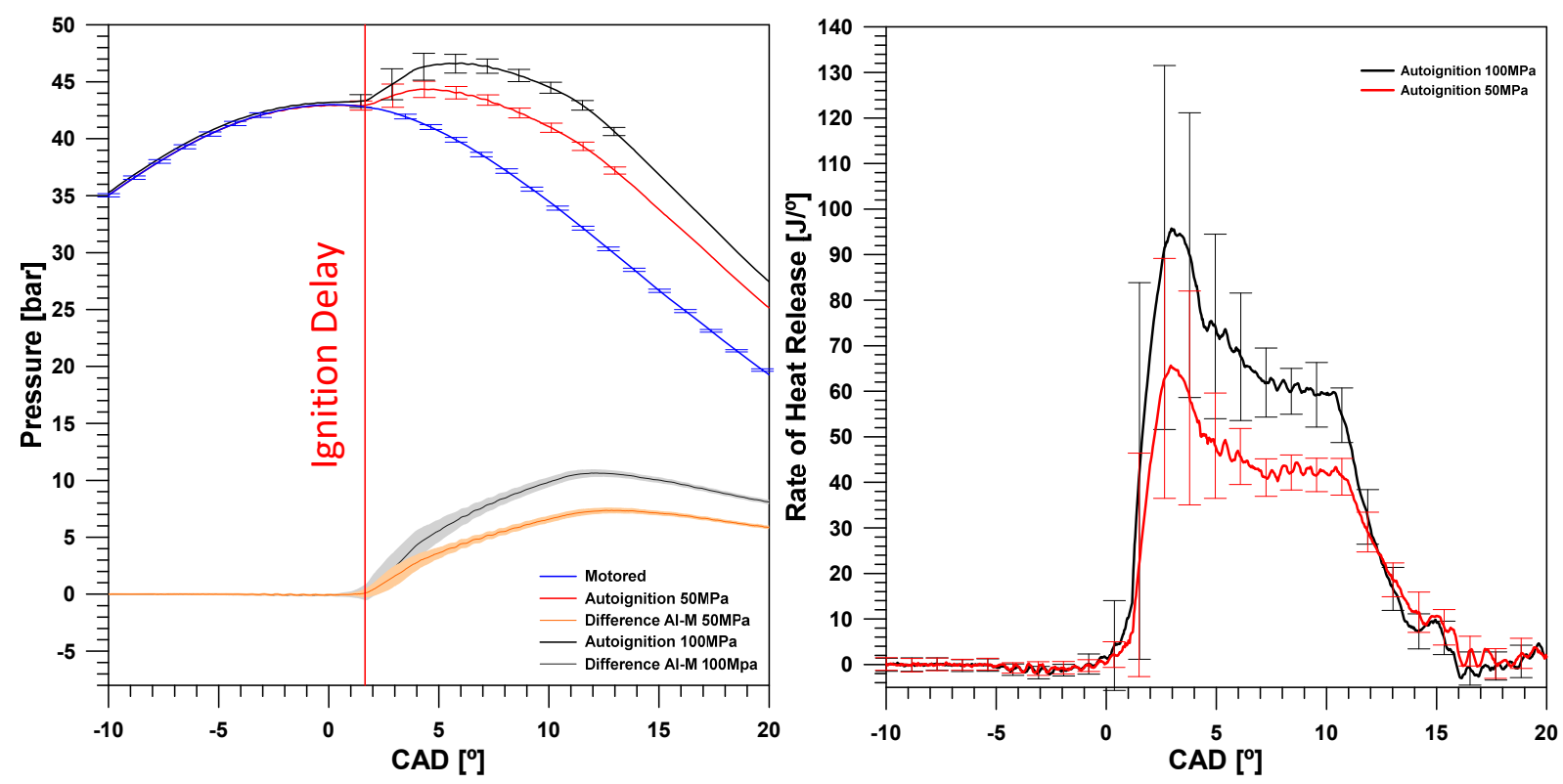

Figure 3 - In-cylinder pressure (left) and Rate of Heat Release (right) evolution for the autoignition reference combustion event at two injection pressure values. The curves showed here are an average of 50 repetitions. The standard deviation is reported as vertical error bars along the average curve. The difference between firing and motored cycles is also reported at the bottom, as a clear indicator of the start of combustion.

Every registered pressure acquisition event consists of a pair of engine cycles, the first one under motored, the second one under firing conditions. The direct comparison of the two consecutive pressure curves, permits the detection of the ignition event when the in-cylinder pressure evolution starts to raise over the engine motored compression pressure curve, as can be seen in Figure 3 . The ignition delay is defined as the time elapsed from the Start of Injection (Sol) until a steep rise of the pressure in the chamber is detected two times greater than the standard deviation of the pressure difference, and could be visualized on the pressure curves reported in Figure 3 . As an example, this figure shows the evolution of pressure in the combustion chamber in comparison with a motored pressure curve (i.e. without fuel injection), and the rate of heat release evolution, calculated with a combustion diagnostic code, for the same reference combustion event.

\section{EXPERIMENTAL RESULTS}




\subsection{Experimental Test Matrix}

All the measurements presented in this paper have been performed at fixed engine conditions, with standard dry air $\left(21 \% \mathrm{O}_{2}\right)$, inside the range of operation of current automotive DI Diesel engines. Thermodynamic conditions of the intake air where selected in order to achieve, under motored conditions, in-cylinder peak pressure of $5.3 \mathrm{MPa}$ and peak temperature of $700 \mathrm{~K}$, which leads to a mean density value of $21.7 \mathrm{~kg} / \mathrm{m} 3$ during the injection.

A single shot injection was performed per cycle with an energizing time of $5600 \mu$ s and a Start of Energizing (SOE) of 6.5 CAD BTDC. Two values of injection pressure, 50 and $100 \mathrm{MPa}$, were tested, and 75 injection cycles were recorded in every condition. It must be underlined that in both cases injection duration is too long if compared with more typical real engine application values. However, it was selected on purpose to ensure a nearly steady spray so that the effect of induced ignition upon spray combustion evolution was not masked by effects inherent to transient spray development.

The selection of two different values of injection pressure is only motivated by the need to enlarge the range of conditions and locations achievable to generate a laser plasma which could provoke fuel ignition. It seems evident from Figure 3 that for the autoignition cases, combustion at the two different ignition pressures starts almost at the same time, but due to the different amount of fuel present in the chamber, the subsequent development, although similar, is just shifted to higher pressure and heat release rates for the highest injection pressure.

Regarding autoignition delay for this reference case, injection pressure has shown no sensitive effect, as expected, with measured differences far smaller than the experimental uncertainty, which indicates a low cycle to cycle repeatability. Thus, for tests at $50 \mathrm{MPa}$ injection pressure, an average auto-ignition delay time of $2613 \mu$ s was measured with a standard deviation of $200 \mu \mathrm{s}$. In the case of 
$100 \mathrm{MPa}$ injection pressure, the average ignition delay time was $2540 \mu \mathrm{s}$ with a standard deviation of $260 \mu \mathrm{s}$. It will be shown latter in this paper that the plasma induction has an important stabilization effect on the ignition delay time, and some effect on the heat release evolution, too.

For these reference conditions, which are here referred as baseline autoignition cases, several Laser Induced Plasma test cases have been considered. Plasma has been generated, with the same optical arrangement and laser settings for all the cases, at 10 different timings (between 0.4 and $1.6 \mathrm{~ms}$ ASOE) for a fixed distance from the nozzle $(16 \mathrm{~mm})$ to analyze the effect of plasma generation timing. In order to study the effect of laser plasma generation location in the spray, 4 different plasma locations (within 6 to $21 \mathrm{~mm}$ from the nozzle) at a fixed timing (0.8 ms ASOE) have been measured. These values, which are here reported in Table 2 and also marked in Figure 6 and Figure 7 to facilitate the discussion of results, were selected after a preliminary study (not detailed here for brevity), to sweep a fair range of fuel/air ratios at the site of ignition. For every laser plasma location and timing, a total of 30 cycles where registered applying both Schlieren visualization technique and flame soot broadband imaging.

\begin{tabular}{|c|c|c|c|c|c|c|c|c|c|c|c|}
\cline { 3 - 13 } \multicolumn{2}{c|}{} & \multicolumn{8}{c|}{ LIP Generation Delay Time (ASOE) [ms] } \\
\cline { 3 - 14 } & & 0.4 & 0.5 & 0.6 & 0.7 & 0.8 & 0.9 & 1 & 1.2 & 1.4 & 1.6 \\
\hline \multirow{4}{*}{$\begin{array}{c}\text { Distance from Injector Nozzle } \\
{[\mathrm{mm}]}\end{array}$} & 11 & & & & & $\mathrm{X}$ & & & & & \\
\cline { 2 - 13 } & 16 & $\mathrm{X}$ & $\mathrm{X}$ & $\mathrm{X}$ & $\mathrm{X}$ & $\mathrm{X}$ & $\mathrm{X}$ & $\mathrm{X}$ & $\mathrm{X}$ & $\mathrm{X}$ & $\mathrm{X}$ \\
\cline { 2 - 12 } & 21 & & & & & $\mathrm{X}$ & & & & & \\
\hline & 26 & & & & & $\mathrm{X}$ & & & & & \\
\hline
\end{tabular}

Table 2 - Laser Induced Plasma generation timings and positions selected for the reported study

\subsection{Reference spray evolution and LIP location selection}

When a Diesel spray is injected into the chamber, Schlieren technique has proved to be a fair tool to track spray tip penetration, not only under inert conditions but also in reacting sprays before 
ignition, or when flame kernel has progressed. However, whenever the spray density becomes that of the bulk gas in the chamber, which may occur in some cases just before, during or just after fuel ignition, the detection of the actual spray boundaries is not always easy, if possible [25]. To overcome such difficulty, every repetition of every tested case was registered with the high-speed CMOS camera using both the Schlieren method and the Natural Flame Luminosity emission for the spray and sooting flame visualization. An example of the obtained visualization images and sprays evolution are here reported in Figure 4 for the Schlieren imaging and in Figure 5 for the soot radiation.

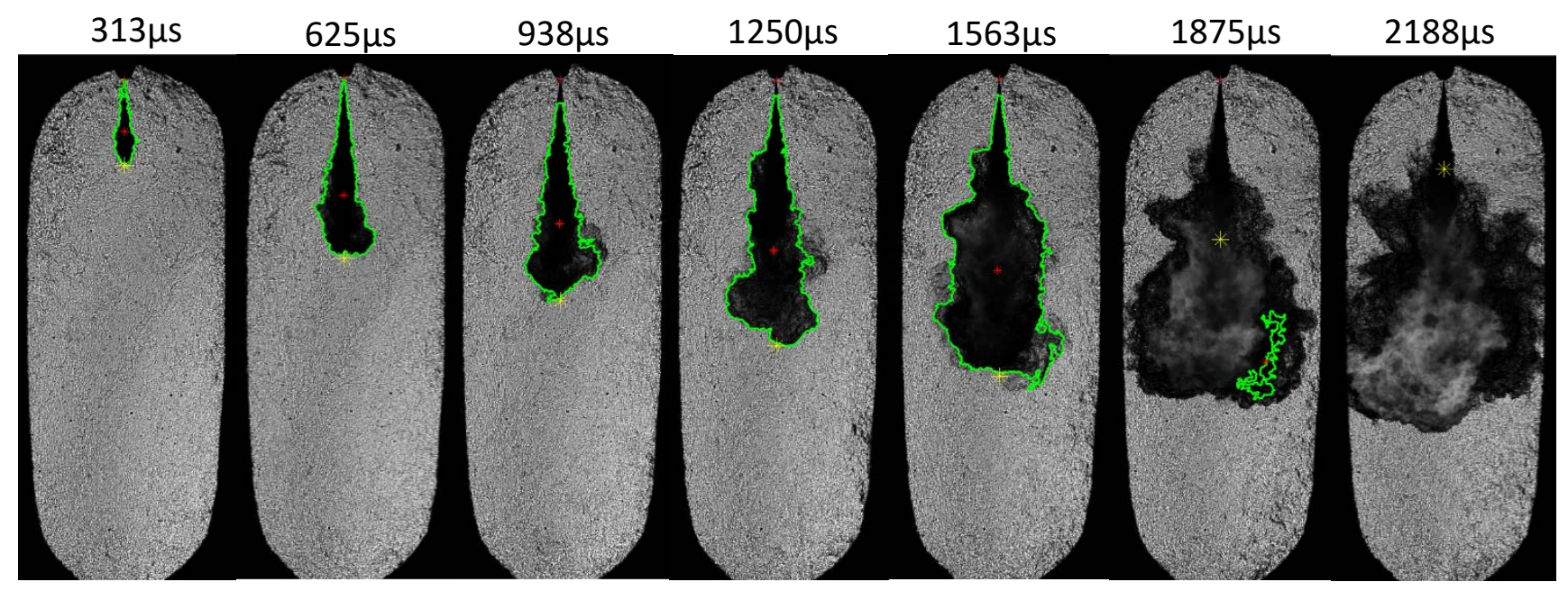

Figure 4 - Example of spray vapor phase evolution inside the combustion chamber as derived from the application of Schlieren technique. Spray contours as obtained by the image processing code are also overlaid on the images to show the difficulties of the contour detection algorithm when the emission from the soot cloud appears after the ignition. The red and yellow points reported in the images comes also from the image processing code and indicates the center of mass of the detected contour area (red point) and the spray penetration as detected by a secondary processing method applied to the same images (yellow). The reported images are taken from a 5.3MPa, 765K@TDC case, with Diesel injected at 500MPa and ignited with laser induced plasma at 11mm from the nozzle and 0.8ms ASOE. All the reported times are defined After Start of Energizing (ASOE). 


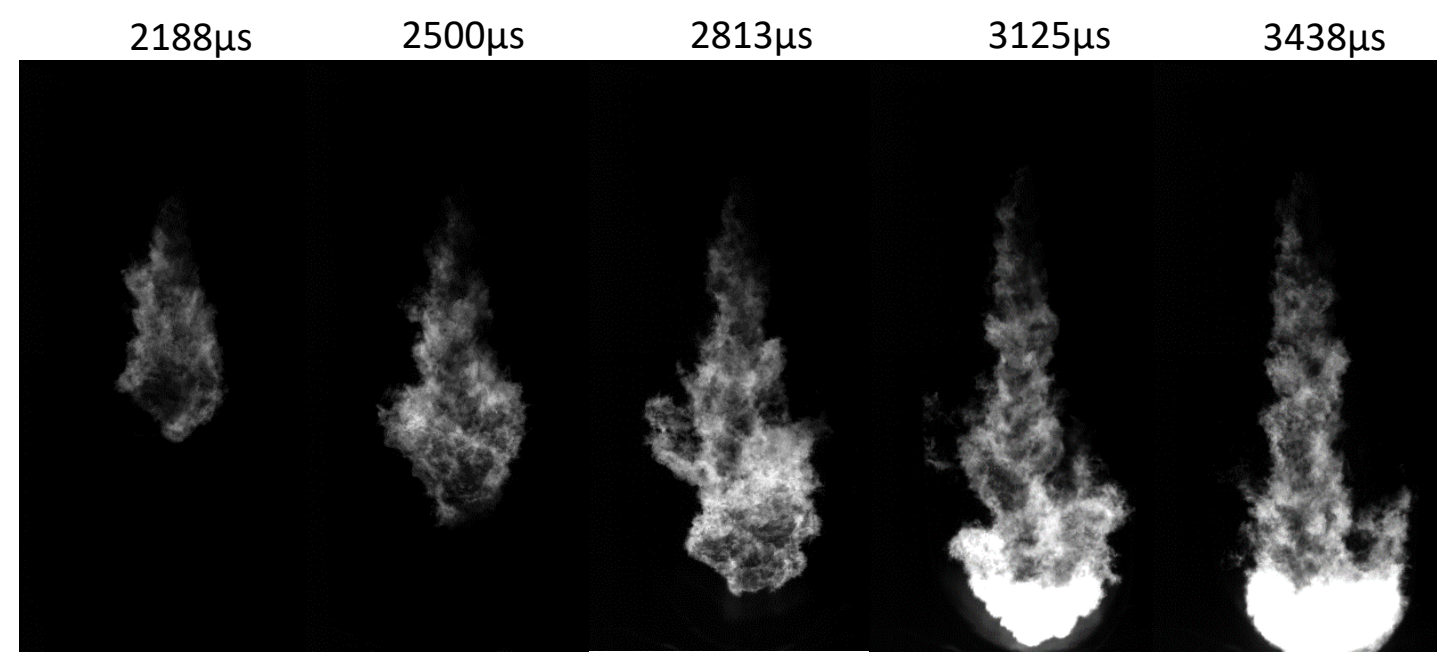

Figure 5 - Example of spray evolution inside the combustion chamber as derived from the application of Natural Luminosity technique once the soot emission appears. The reported images are taken from a 5.3MPa, 765K @TDC case, with Diesel injected at 50MPa and ignited with laser induced plasma at $11 \mathrm{~mm}$ from the nozzle and $0.8 \mathrm{~ms}$ ASOE. All the reported times are defined After Start of Energizing (ASOE).

Both techniques were focused on the analysis of the spray evolution under reactive conditions, with the aim to see how plasma induced ignition affected spray and flame development. Although the settings of the Schlieren can be chosen in such a way that flame luminosity is suppressed and automatic detection of the spray boundaries can be made confidently [25], in this work Schlieren systems settings were chosen just to avoid blooming effects on the camera, but making the sooting flame clearly visible. It was found to be more convenient to enhance the effects of the plasma induced ignition. However, this configuration decreased dramatically the accuracy of the segmentation procedures and wrong detection of the flame boundaries quite often occurred, as could be seen in the last frames reported in Figure 4. Instead of investing efforts in the improvement of the detection algorithm, which is out of the scope of the objectives of this work, a simpler procedure was used when necessary to combine information from the two imaging methods, in order to obtain a penetration curve for the entire visible range, by discarding those Schlieren images in which flame boundary was apparently not properly detected. 
Thus, Figure 6 shows the penetration curve for the spray under conventional combustion (with autoignition) for both injection pressures, combining experimental information from different sources: First, spray penetration from the Schlieren technique is drawn. Then flame penetration is plotted with a solid line, representing the average value as obtained either from Schlieren measurements (when it is possible) and/or natural luminosity imaging (i.e. broadband emission imaging). The shadowed area width corresponds to \pm the standard deviation. In addition, spray penetration of the liquid and vapor phases as obtained respectively from Mie scattering and Schlieren imaging of the spray injected into an inert ambient (obtained in additional tests not detailed here for brevity) but at the same ambient and injection conditions are plotted for the first 1500 us after SOE.
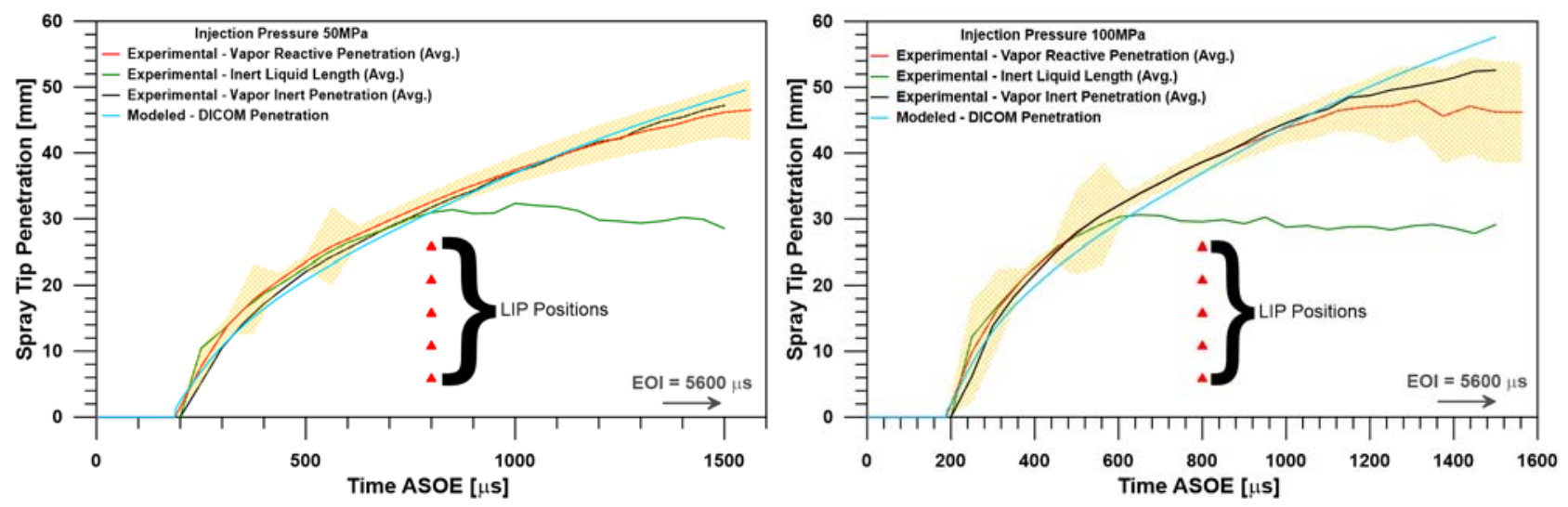

Figure 6 - Modeled/Experimental Spray Penetration curves comparison for DICOM model spray evolution validation.

First of all is important for the subsequent analysis on the plasma ignition underline how in a normal autoignition event the soot signal registered with the natural luminosity technique is a good indicator for the spray penetration in the chamber since the local conditions at the spray tip allows the ignition and combustion of the mixture. So, if the flame kernel is formed in the spray tip, the broadband emission signal recorded can be directly used to measure the spray penetration as a substitute of the Schlieren imaging after ignition, thus avoiding saturation effects and postprocessing problems that could arise from the application of the Schlieren visualization in presence 
of the broadband emission of a flame. In this sense, later in this paper will be shown how forcing the ignition with plasma could cause a shift in the position between the registered soot signal and the real tip of the spray penetration, since the generation of the flame kernel does not occur anymore at the tip zone of the spray, leading to the impossibility to match the Schlieren and Natural Luminosity penetration curves.

Second, comparing the penetration curves obtained for the autoignition in inert and reactive cases, the expected spray acceleration in the reacting versus the inert spray reported in [26] cannot be so clearly seen here, probably due to the peculiarities of the in-chamber air flow that causes an appreciable slowdown of the spray [27]. This feature of the experimental facility has been taken into account to define position and timing of the laser plasma ignition, so that the start of ignition was forced in a location where air flow intensity was not so high as to disturb the spray/flame structure.

Third, in order to get an idea about the local conditions on the locations where plasma should be created and to facilitate analysis, spray evolution was simulated with a 1-D spray model [28] [29], which uses injection rate and spray cone angle as two major inputs to solve the mass and momentum conservation equations. The penetration curve obtained from this simulation is plotted in Figure 6, and the local relative equivalence ratio at the spray centerline is given in Figure 7. In both figures, the symbols labeled as LIP positions are plotted to indicate the timing and the local position along the spray axis where the plasma ignition was attempted. It must be noted that all the attempted ignition locations are located at distances to the nozzle below the spray liquid length, i.e. ignition is provoked in a region where fuel has not vaporized completely at the moment of the plasma induction. 
Figure 7 shows the estimated equivalence ratio at the ignition locations as derived from the 1D spray model. Results indicate that all the attempted ignition tests were made in rich mixture conditions. Despite the simplicity of the spray model used indicates that quantitative values should be considered with some caution and equivalence ratio absolute values could be biased, it becomes clear that in all cases attempted fuel mixture was very rich: relative fuel/air ratio between 28 and 2 where obtained for the $50 \mathrm{MPa}$ injection pressure case, and between 18 and 2 for the $100 \mathrm{MPa}$ pressure. It should be also underlined that a high local fuel/air ratio variation appears between the two points closest to the nozzle $(6 \mathrm{~mm}$ and $11 \mathrm{~mm})$ for both pressure conditions. Also remarkable is the fact that the time evolution of the local equivalence ratio indicates a nearly constant value for all the attempted ignition at different induction times probed at $16 \mathrm{~mm}$ from the injector. This is due to the evolution of the spray under quasi-steady conditions. All these considerations about the local conditions at the plasma generation location will be later discussed for the laser ignition cases.
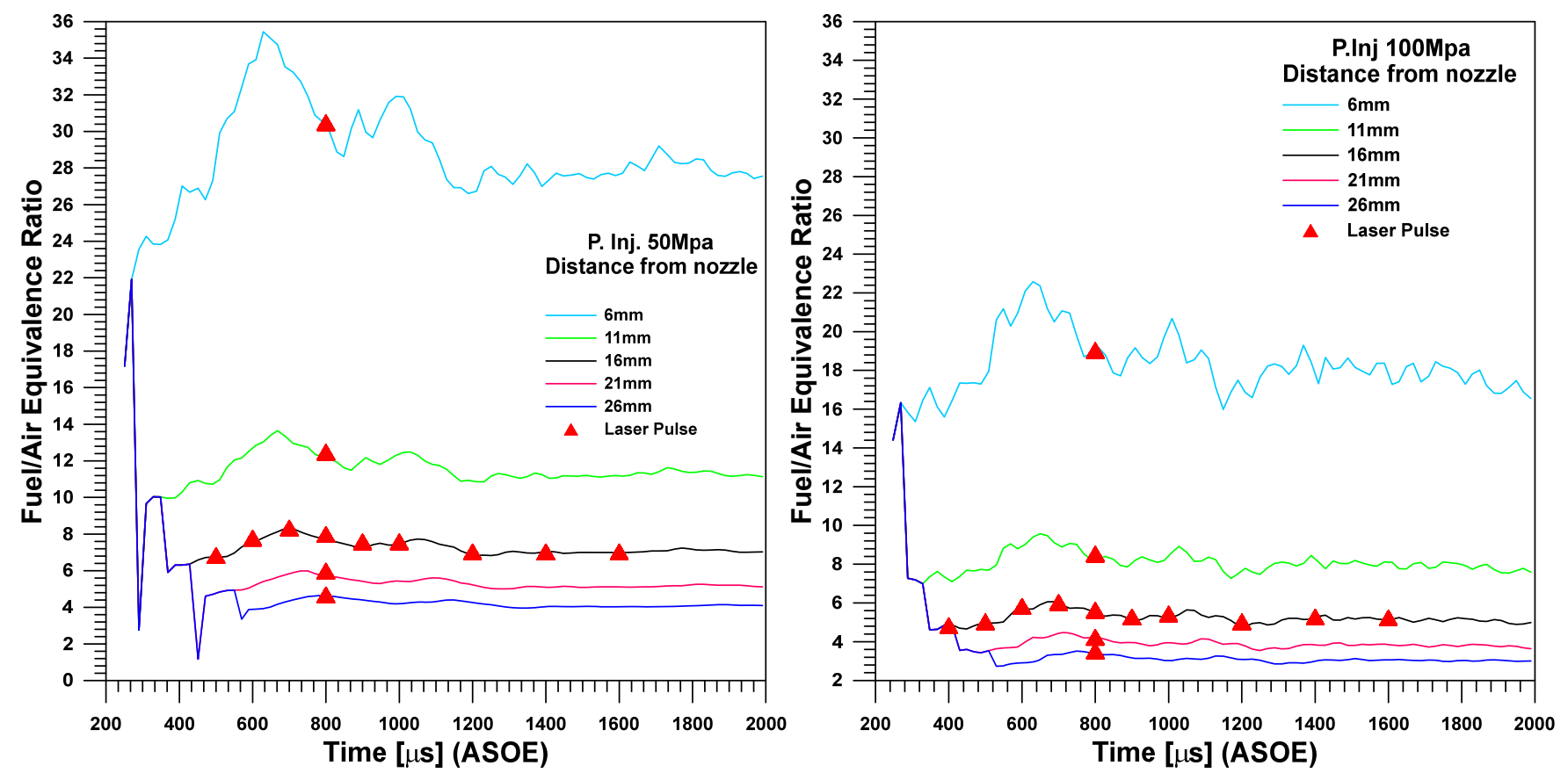

Figure 7 - Local Fuel/Air Equivalence Ratio evolution, as obtained from the DICOM 1D spray model, for the two tested injection pressures (50MPa on the left and 100MPa on the right) at 5,3MPa and 700K. On the graphs are indicated all the attempted LIP ignition positions and timings. 


\subsection{Laser plasma ignition efficiency and success rate}

It is significant that, at the selected experimental conditions, the ignition of the Diesel spray was successfully achieved in all different local points and delay times with the only exception of the injector nozzle's nearest position, namely at $6 \mathrm{~mm}$ from the nozzle, as summarized in Table 3 for the plasma position variation tests and in Table 4 for the plasma laser pulse timing variation tests.

\begin{tabular}{|c|c|c|}
\hline \multirow{2}{*}{$\begin{array}{c}\text { LIP Position (from } \\
\text { nozzle) [mm] }\end{array}$} & $\begin{array}{c}\text { Injection pressure } \\
\text { 50MPa }\end{array}$ & $\begin{array}{c}\text { Injection pressure } \\
\text { 100MPa }\end{array}$ \\
\cline { 2 - 3 } & Ignition Success Rate & Ignition Success Rate \\
\hline 6 & $0 \%$ & $0 \%$ \\
\hline 11 & $47 \%$ & $77 \%$ \\
\hline 16 & $100 \%$ & $93 \%$ \\
\hline 21 & $96 \%$ & $100 \%$ \\
\hline 26 & $100 \%$ & $100 \%$ \\
\hline
\end{tabular}

Table 3 -Summary of the success rates for the LIP ignition tests realized varying the plasma induction position at a fixed laser pulse timing of $800 \mu \mathrm{s}$ ASOE.

All the tests performed with plasma at $6 \mathrm{~mm}$ from the nozzle have had misfiring results even with the maximum available laser pulse energy of almost $800 \mathrm{~mJ}$, i.e. roughly 3 times higher than the power employed for all the other tested cases. This clearly indicates an upper limit for the local equivalence ratio of the mixture that allows a successful ignition with such ignition system. With respect of this success rate analysis and especially referred to the high energy used for the ignition attempts, it must be remarked that all the provoked ignitions were attempted at distances from the nozzle shorter that the liquid length of the spray. So, to reach the ignition condition of the mixture, the energy provided at the local spray location was used to generate free radicals starting from a practically liquid spray or a very high rich mixture. The generation of a sufficient amount of radicals seems to be the key for the success of the forced ignition. 


\begin{tabular}{|c|c|c|}
\hline $\begin{array}{c}\text { LIP Delay (ASOE) } \\
{[\mathrm{mm}]}\end{array}$ & Injection pressure 500bar & Injection pressure 1000bar \\
\cline { 2 - 3 } & Ignition Success Rate & Ignition Success Rate \\
\hline 400 & None & $97 \%$ \\
\hline 500 & $90 \%$ & $100 \%$ \\
\hline 600 & $97 \%$ & $96 \%$ \\
\hline 700 & $93 \%$ & $100 \%$ \\
\hline 800 & $100 \%$ & $93 \%$ \\
\hline 900 & $97 \%$ & $97 \%$ \\
\hline 1000 & $100 \%$ & $97 \%$ \\
\hline 1200 & $97 \%$ & $97 \%$ \\
\hline 1400 & $97 \%$ & $100 \%$ \\
\hline 1600 & $97 \%$ & $100 \%$ \\
\hline
\end{tabular}

Table 4 - Summary of the obtained success rates for the LIP ignition tests realized varying the plasma induction timing at a fixed position of $16 \mathrm{~mm}$ from the nozzle.

\section{RESULTS DISCUSSION: PLASMA INDUCED IGNITION EFFECTS ON}

\section{SPRAY COMBUSTION}

\subsection{Laser plasma effect on the ignition delay time}

The results obtained from the registered pressure curves show how the fuel spray ignition delay, as defined above, varies with the position and the timing of the laser plasma induction. The IgnitionLaser pulse timing is defined as the time from the effective laser shot occurrence until the ignition point.

From the results shown in in Figure 8, it can be appreciated how the ignition delay of the mixture gets larger and the scattering increased as the plasma induction location approaches the injector nozzle. 

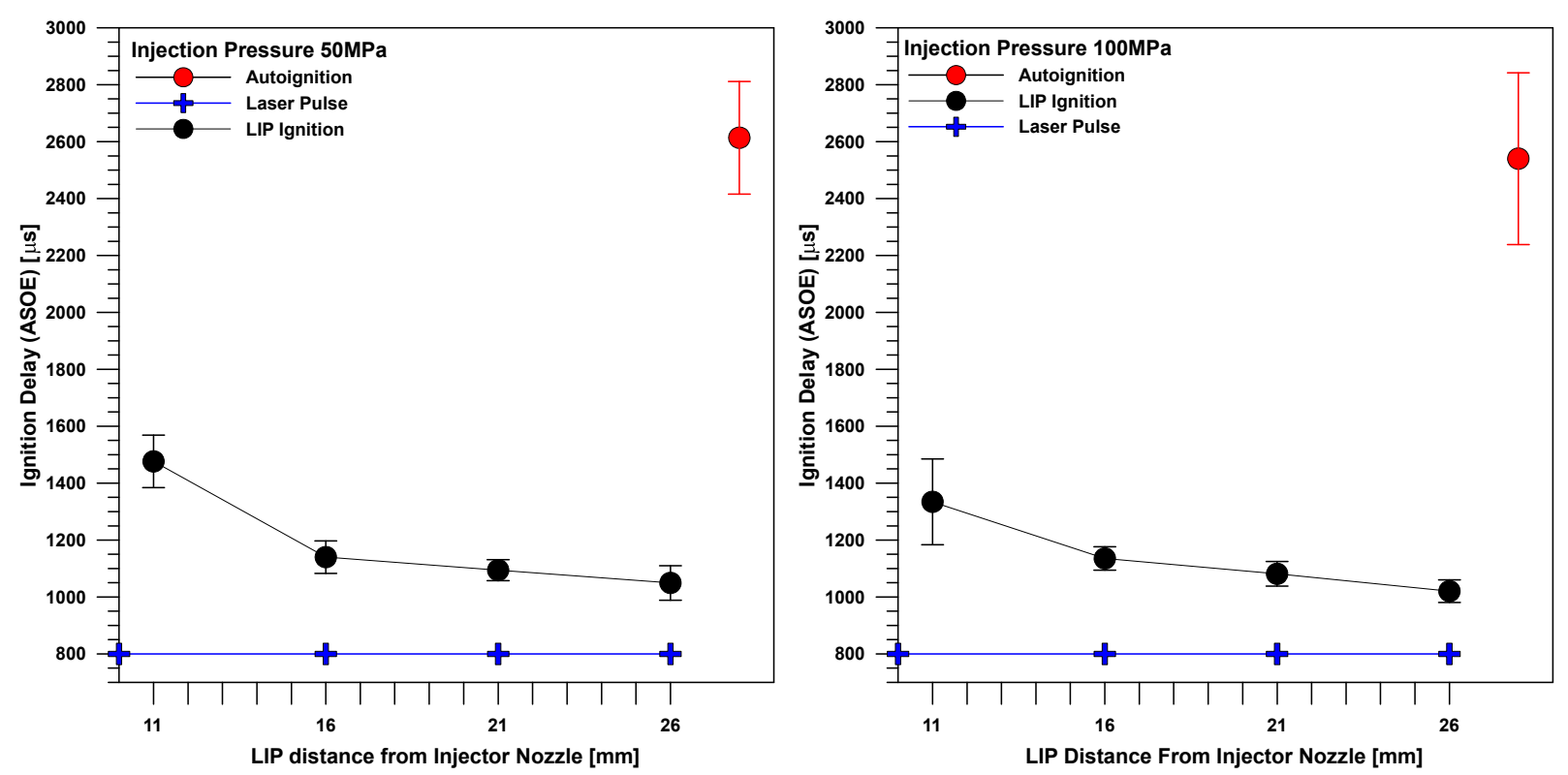

Figure 8 - LIP position effect on combustion ignition delay. The average ignition delay of the autoignition case is also reported for comparison.

These graphs show the evidence of how plasma ignition stabilizes ignition delay limiting the dispersion around the mean value of each case if compared with the autoignition results, where the range of possible ignition delay times is clearly wider. The only exception, if we compare the standard deviations, seems to be represented by the $11 \mathrm{~mm}$ induction position case with $100 \mathrm{MPa}$ injection pressure, where the spray seems to have a transitional or boundary ignitable condition. Generating plasma at $11 \mathrm{~mm}$ from the nozzle and $0.8 \mathrm{~ms}$ of delay with respect the start of energizing seems to have practically the same average $70 \%$ probability of success (for the $100 \mathrm{MPa}$ injection pressure) along a time range of more than $500 \mu$ s. For this reason, this is also the test that has the greater data dispersion compared with all the other cases, as shown in Figure 8.

Concerning the results obtained from the plasma laser pulse timing variation study, a constant linear increase of the ignition delay with the laser pulse timing was found, as seen in Figure 9. These results seems to be logical due to the similarity of the local conditions for the different cases as obtained from the DICOM model (see Figure 7) 

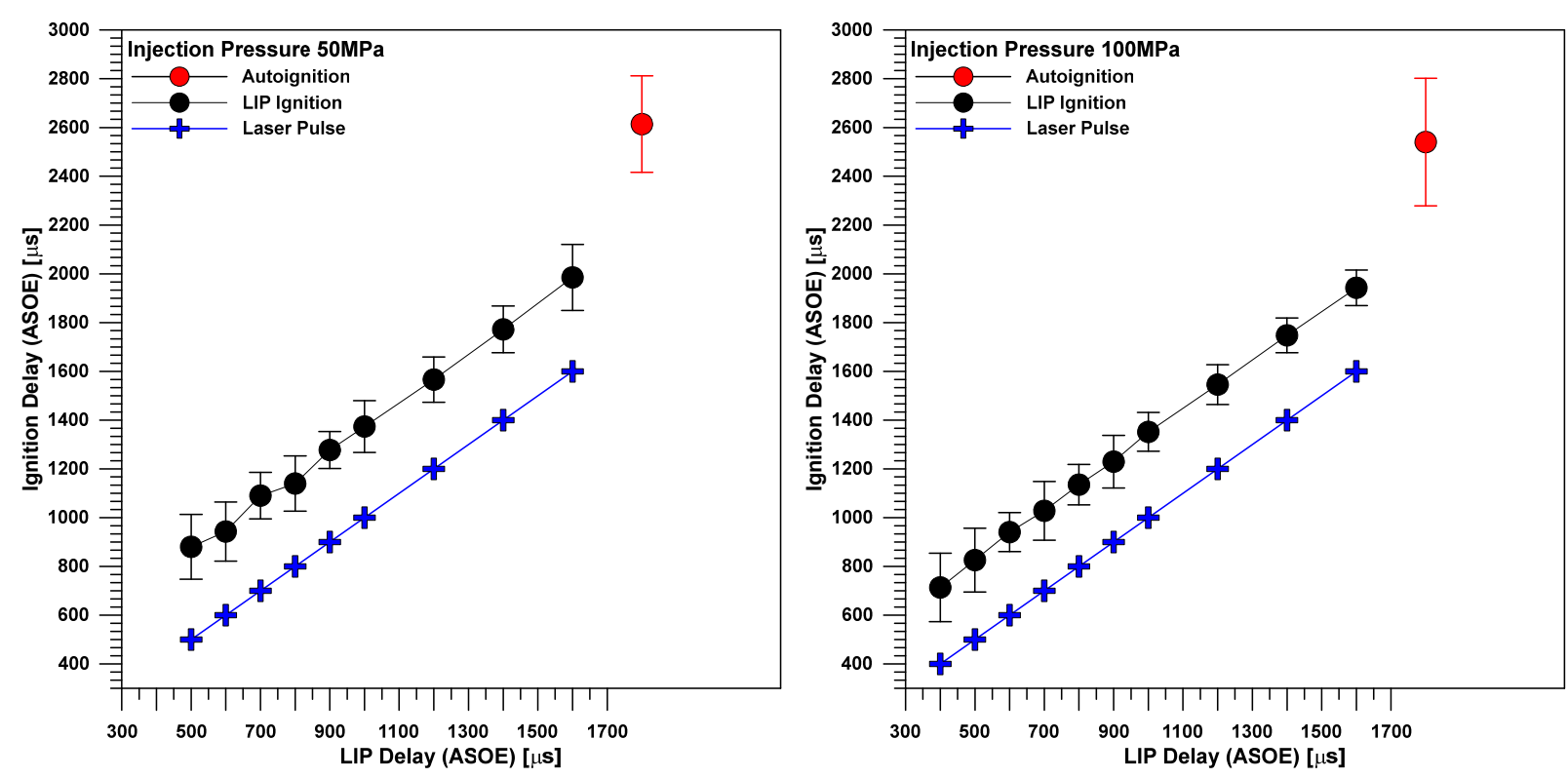

Figure 9 - LIP Timing effect on combustion ignition delay. The average ignition delay of the autoignition case is also reported for comparison.

Standard deviation bars reported in Figure 9 for the laser pulse timing variation still clearly indicates the stabilization effect of the laser plasma induction on the ignition delay if compared with the autoignition case.

From the analysis of all the combustion indicator parameters, it seems that the ignition delay should be considered as the main tracer for the effects of induced ignition upon fuel combustion. It also seems that the ignition delay should be linked to the local flow conditions at the ignition location and timing. However, there are other parameters which should allow understanding and quantifying the effect of provoked ignition upon fuel combustion and subsequent engine performance. These are considered in the following sections.

\subsection{Laser plasma effect on heat release rate}

A fundamental parameter for the combustion diagnostic and for the analysis of the plasma ignition effect is represented by the Rate of Heat Release (RoHR) curves, which have been calculated, in this 
case as Apparent RoHR, for each tested ignition case. It must be reminded that their shape would be quite different to those typical of Diesel engines for automotive applications since both injection duration and combustion chamber volume are quite different too. However, comparison of these curves between the conventional case with autoignition and those of plasma induced ignition should help to identify and illustrate the effects.

In terms of plasma induction location variation, it could be seen in Figure 11 that, as the plasma induction region approaches the injector nozzle, the energy release gets lower. The same effect could be appreciated for the laser pulse timing variation: as the laser pulse timing time gets shorter, combustion starts earlier and the total heat released in the chamber gets higher even if the theoretical local mixture equivalence ratio is constant, as obtained from the spray model.

Again, from the ARoHR curves reported for the plasma position variation in Figure 10, it could be seen how as the induction position moves farther from the nozzle, the resulting combustion varies progressively from a typical premixed combustion, similar to the one of the autoignition case, to a more homogeneous diffusive combustion, with a first rapid mixing-controlled phase and a subsequent steady phase that lasts till the end of injection. 

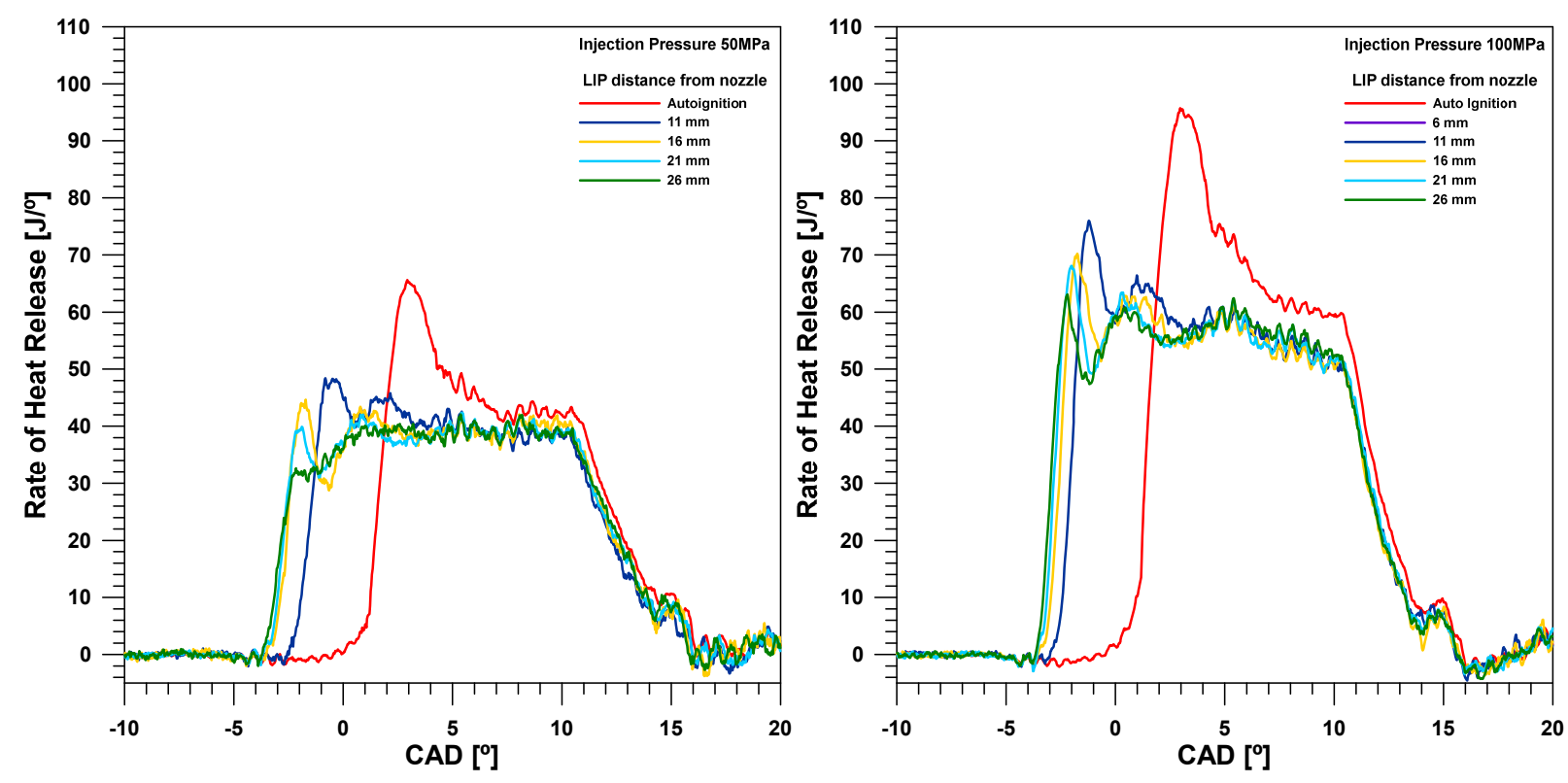

Figure 10 - Apparent Rate of Heat Release curves for the two injection pressure as obtained for the variation of the inducted plasma position. RoHR curve for the autoignition case is also reported as reference.
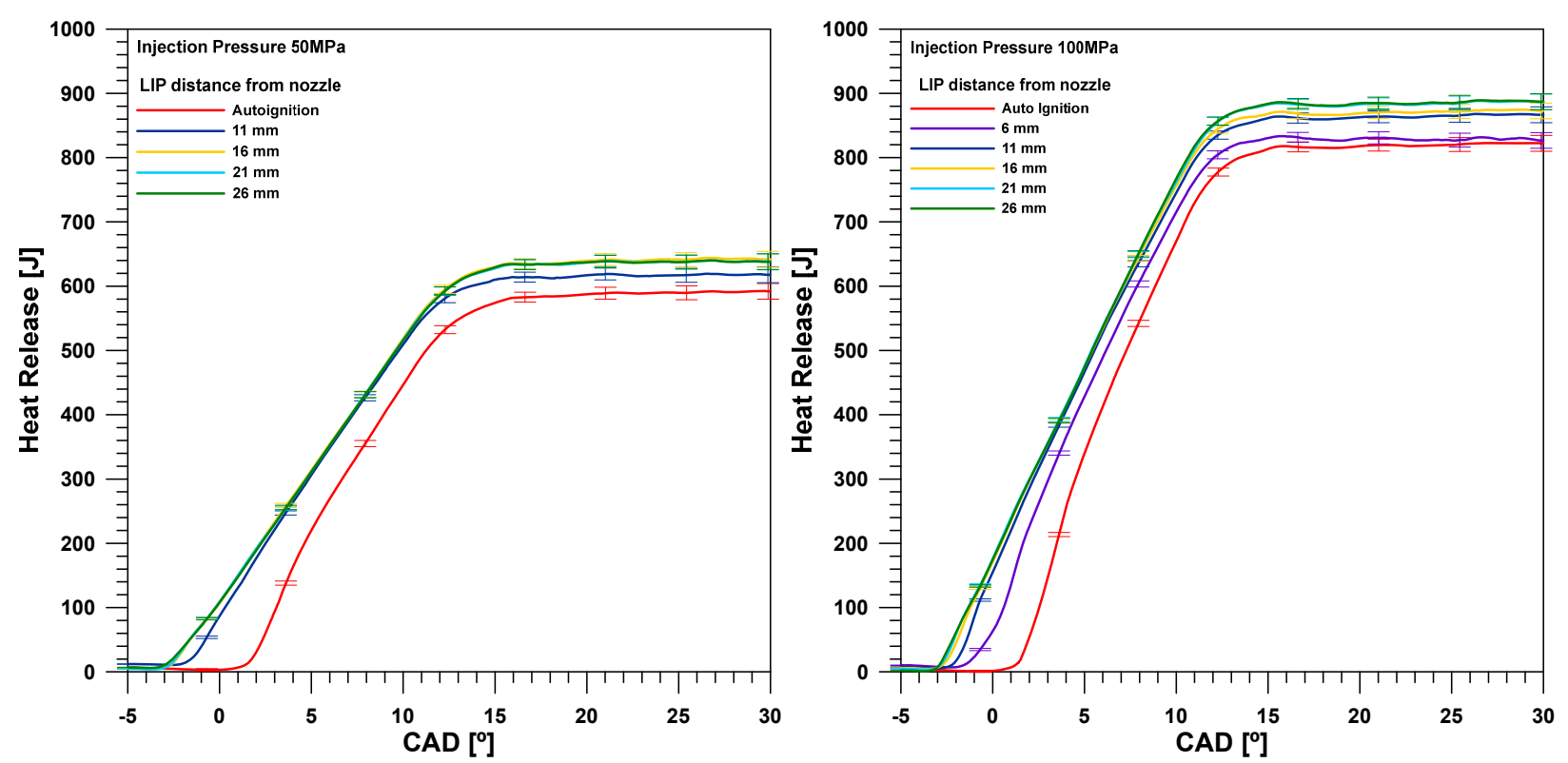

Figure 11 - Apparent total Heat Release curves for the two injection pressure as obtained for the variation of the inducted plasma position. HR curve for the autoignition case is also reported as reference.

The same behavior is appreciable in Figure 12 for the plasma induction time variation tests, where the premixed peak progressively disappears as the laser pulse timing time gets shorter. In both cases 
the disappearance of the premixed peak in the ARoHR curves is paired with a higher total heat release of the combustion, as could be appreciated from the Heat Release curves reported in Figure 11. All the tests were realized with the same injection parameters in terms of fuel quantity (energizing time) and timing (SoE). In a more detailed analysis it can be appreciated that for the low injection pressure test at the furthest induction position from the nozzle $(26 \mathrm{~mm})$, and for the high injection pressure at the shortest laser pulse timing time $(0.4 \mathrm{~ms})$, the ARoHR curves do not present any premixed-combustion peak. Those are the only conditions of the whole test matrix that presents a pure diffusive combustion development, reflected in the highest heat release for both injection pressures.
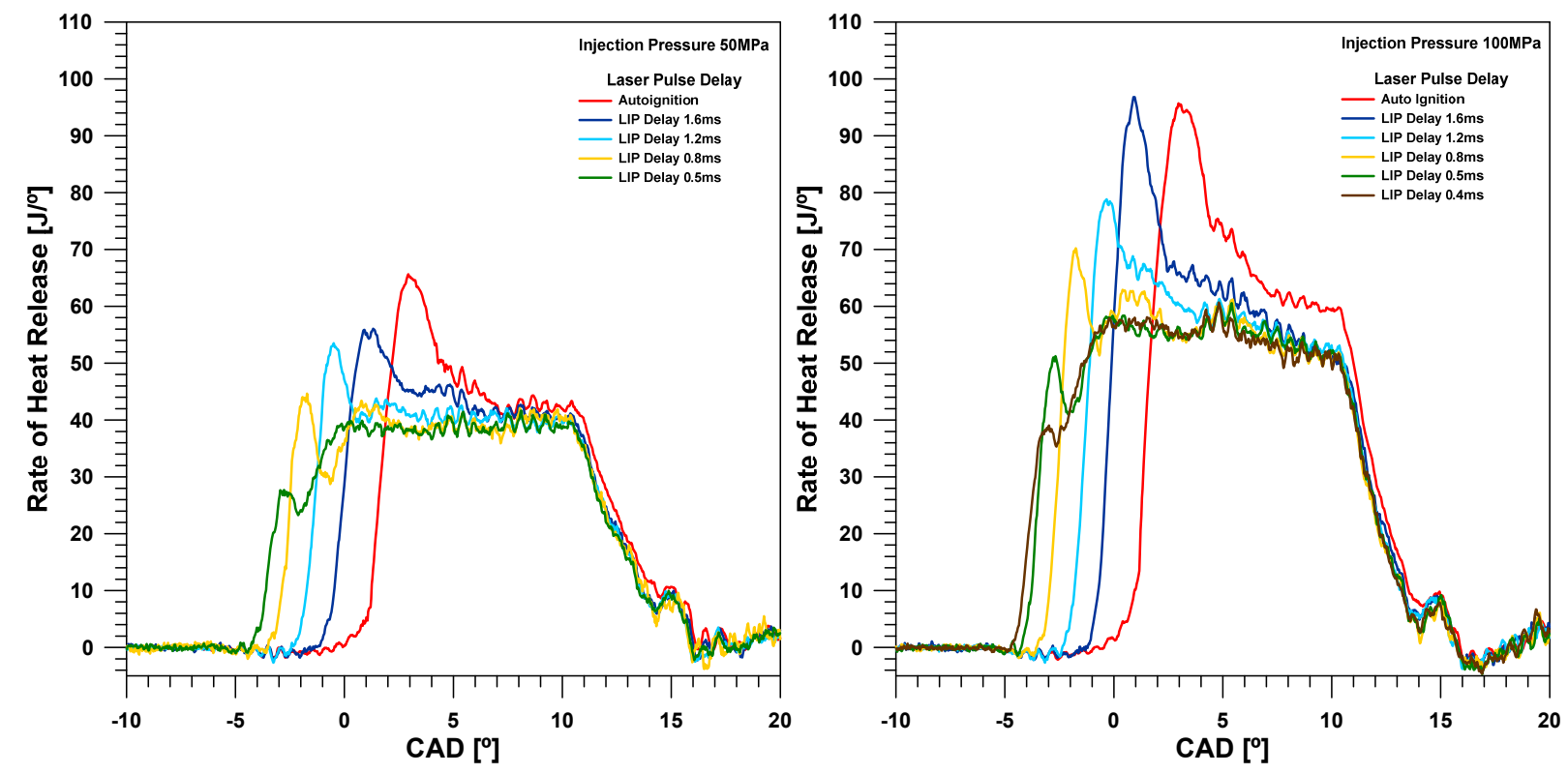

Figure 12 - Apparent Rate of Heat Release curves for the two injection pressure as obtained for the variation of the inducted plasma timing from the start of energizing. RoHR curve for the autoignition case is also reported as reference.

This should be an indicator of how the relative ignition delays of $1049 \mu \mathrm{s}$ for the $26 \mathrm{~mm} / 0.8 \mathrm{~ms}$ plasma induction at $50 \mathrm{MPa}$ of injection and $713 \mu \mathrm{s}$ for the $16 \mathrm{~mm} / 0.4 \mathrm{~ms}$ induction at $100 \mathrm{MPa}$ of injection are not allowing a sufficient mixture formation before the start of combustion. But in fact, for the $50 \mathrm{MPa}$ injection pressure case, analyzing all the obtained ignition delay values, this ignition condition does not correspond to the lowest ignition or ignition-laser pulse timing achieved, but it 
is the only case where the premixed peak cannot be found. For example, an earlier ignition attempt at $0.5 \mathrm{~ms}$ of delay ASOE at $16 \mathrm{~mm}$ from the nozzle, which involves a shorter laser pulse timing of $880 \mu$ s, still presents a small premixed combustion peak where the commented cases do not. The reason for the observed difference should be probably due to the relative position of the plasma with respect the spray tip and the local equivalence ratio of the mixture. As could be seen from Figure 6 and Figure 7 , the induction position at $0.5 \mathrm{~ms}$ and $16 \mathrm{~mm}$ from the nozzle is located in the tip zone of the spray and the local equivalence ratio should be higher than that of the $0.8 \mathrm{~ms}$ attempt at $26 \mathrm{~mm}$ from the nozzle. The effect of the local temperature variation must also be considered for a complete analysis. In a closer position to the injector nozzle, local temperature should be lower, which implies that some part of the deposed plasma energy should be used to raise the temperature to the fuel vaporization level, acting as a local energy sink. However the temperature effect will be, if compared to the large variation in terms of local equivalence ratio predicted from the 1D spray model. For this reason, it can be considered that the same amount of energy is used in this case for generating radicals in a richer mixture but in a closer position to the nozzle. This, joined with the effect of a lower local temperature, lead to a delay in the start of combustion, as the ignition occurs only when a critical amount of radicals has been accumulated. For this reason, the flame kernel formation take place in a zone further from nozzle. Meanwhile, the time elapsed to reach a critical radicals value has also allowed the formation of a local leaner mixture, which now burns as soon as the combustion starts. In the other case, the further position and the leaner local mixture of the spray lead to ignition in a zone where the local mixture should not be completely formed, and so cannot burn at the very beginning of the combustion, leading to a diffusion driven combustion. In this case the flame kernel can grow only as long as the fuel injection continues. This analysis puts in evidence how the ignition delay parameter for the combustion diagnostic cannot explain just by itself all the differences in combustion evolution. 
From all the obtained short ignition delay cases it is so clear how a reduction in the premixed combustion peak comes paired with a second rapid combustion phase. This indicates a fast mixture formation during the combustion development in the instants immediately following the first generation of a flame kernel.

\subsection{Laser plasma effect on the spray tip penetration}

On the other hand, the spray tip penetration is a relevant parameter of comparison in the analysis of the laser ignition effect and, more in general, in the analysis of the provoked advanced ignition effect with respect to the conventional autoignition case.

From the penetration graph reported in Figure 13 for the plasma position variation and in Figure 14 for the laser pulse timing variation for both injection pressures, it can be seen that all the provoked ignition cases reported are characterized by a penetration faster than that of the autoignition reference. In this sense, a more detailed comparison between the obtained spray tip penetration for the LIP provoked ignition cases is reported as relative penetration evolution (the difference between the LIP provoked ignition spray penetration and the autoignition reference) for both injection pressures in Figure 15 and Figure 16, respectively for the LIP position variation and LIP timing variation. The obtained faster penetration for the LIP cases could be expected since an earlier start of combustion would lead earlier to a penetration curve driven by the flame expansion, and so to an earlier acceleration of the penetration curve as discussed in [30]. Results show that the provoked ignition penetration curves get progressively away from the autoignition one as the ignition delay time is reduced. It is also important to remind, for the complete understanding of the reported penetration curves, how the slowdown effect of the internal combustion chamber air flow due to the piston movement affects the penetrations curves, particularly for the $100 \mathrm{MPa}$ injection 
pressure cases where the effect is amplified by the higher penetration velocity due to the higher momentum of the spray. Furthermore, this difference is emphasized by the fact that the autoignition presents an average ignition timing that occurs when the spray has already penetrated in the slowdown zone while, thanks to the shortest provoked ignitions delays, in the laser ignition cases the combustion starts before such zone. This lead to even more important difference in the penetration curves, as could be clearly appreciated in the results reported as relative penetration in Figure 15 and Figure 16, especially for the 100MPa injection cases. As for the laser ignition cases the flame-driven acceleration in the spray penetration compensates the discussed slowdown effect, this effect appears to be even more evident, whereas in the autoignition reference case this compensation effect is never occurring.
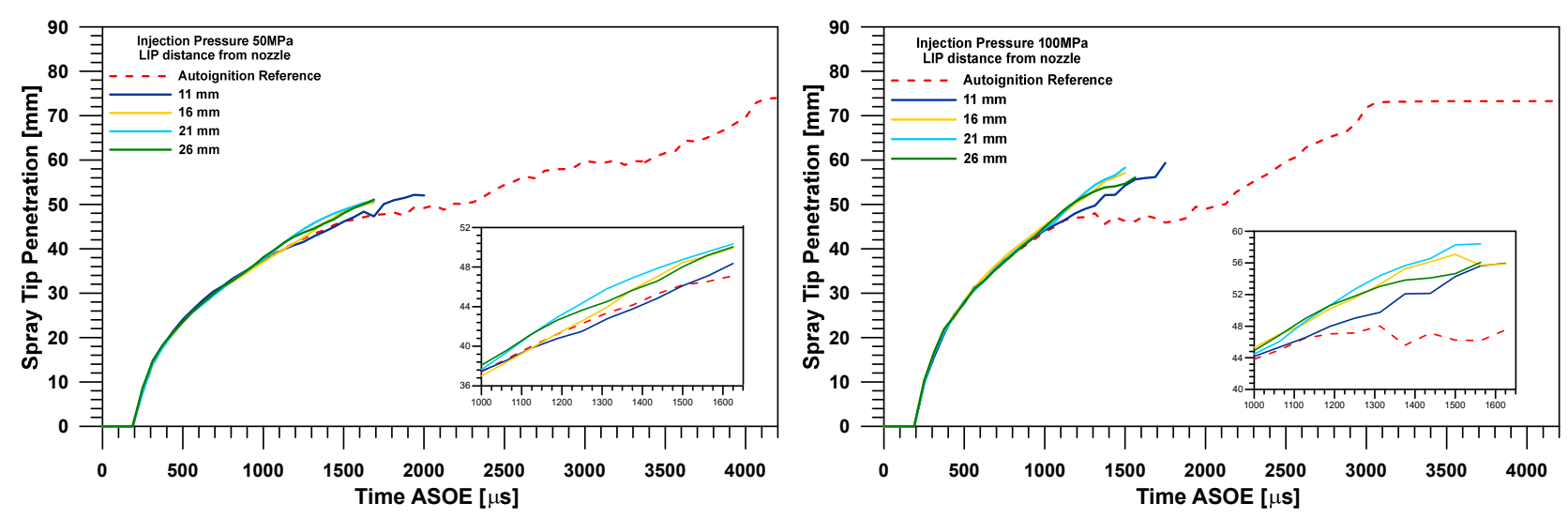

Figure 13 - Tip penetration curves comparisons for the inducted plasma position variation tests at 50MPa (left) and 100MPa (right) injection pressure with a fixed LIP delay time of $0.8 \mathrm{~ms}$ ASOE. The tip spray penetration for the autoignition reference is also reported as a red dashed line. A magnification of the most interesting area is also showed. 

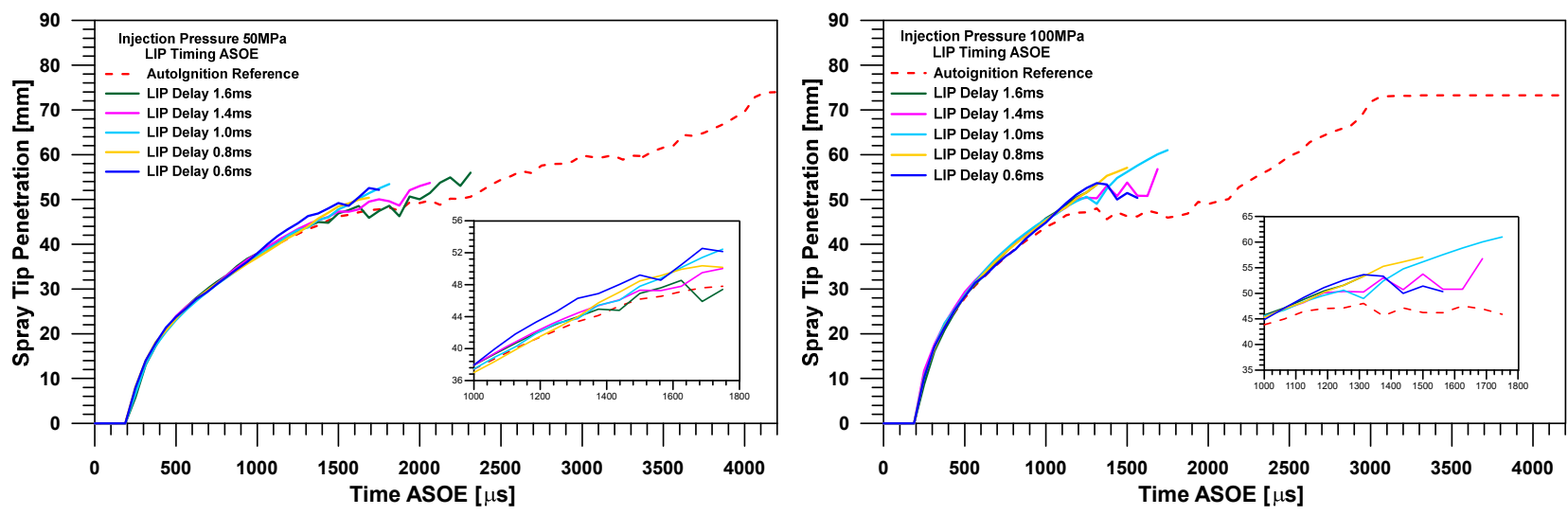

Figure 14 - Tip penetration curves comparisons for the inducted plasma delay variation tests at 50MPa (left) and 100MPa (right) injection pressure with a fixed LIP position of $16 \mathrm{~mm}$ from the injector nozzle along the spray axis. The tip spray penetration for the autoignition reference is also reported as a red dashed line. A magnification of the most interesting area is also showed.
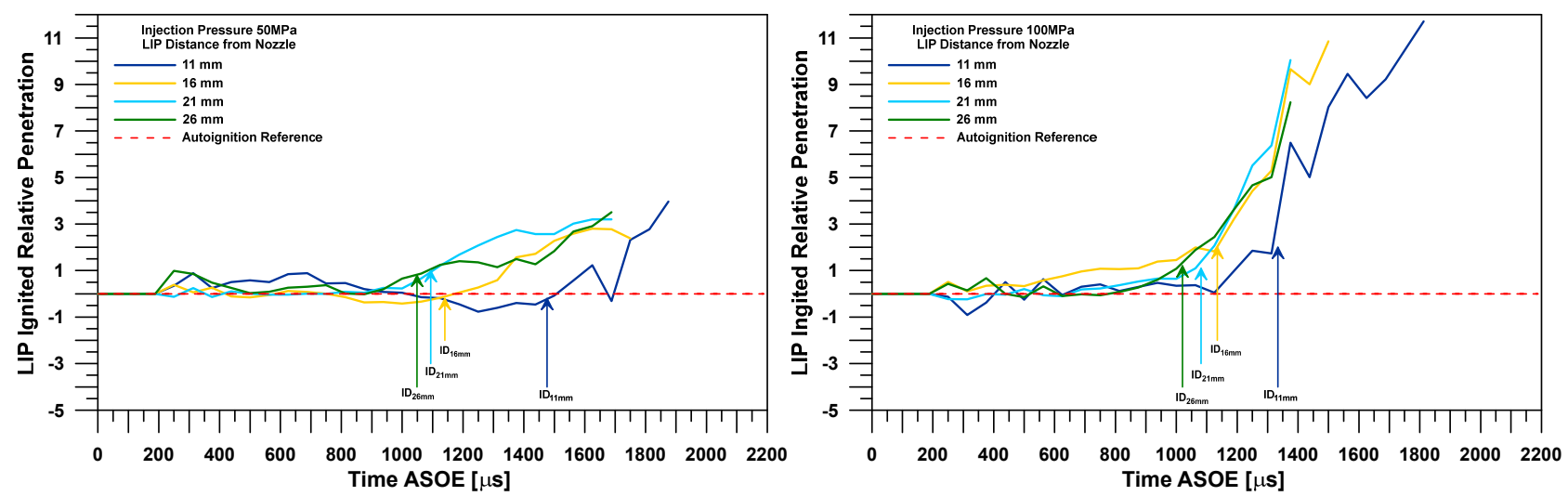

Figure 15 - Relative penetration with respect the autoignition reference (S $\left.S_{\text {lip }}-S_{\text {auto }}\right)$, obtained for the LIP position variation along the spray axis for both injection pressures of 50MPa and $100 \mathrm{MPa}$. The obtained ignition delay for each test case is also indicated in the graphics. 

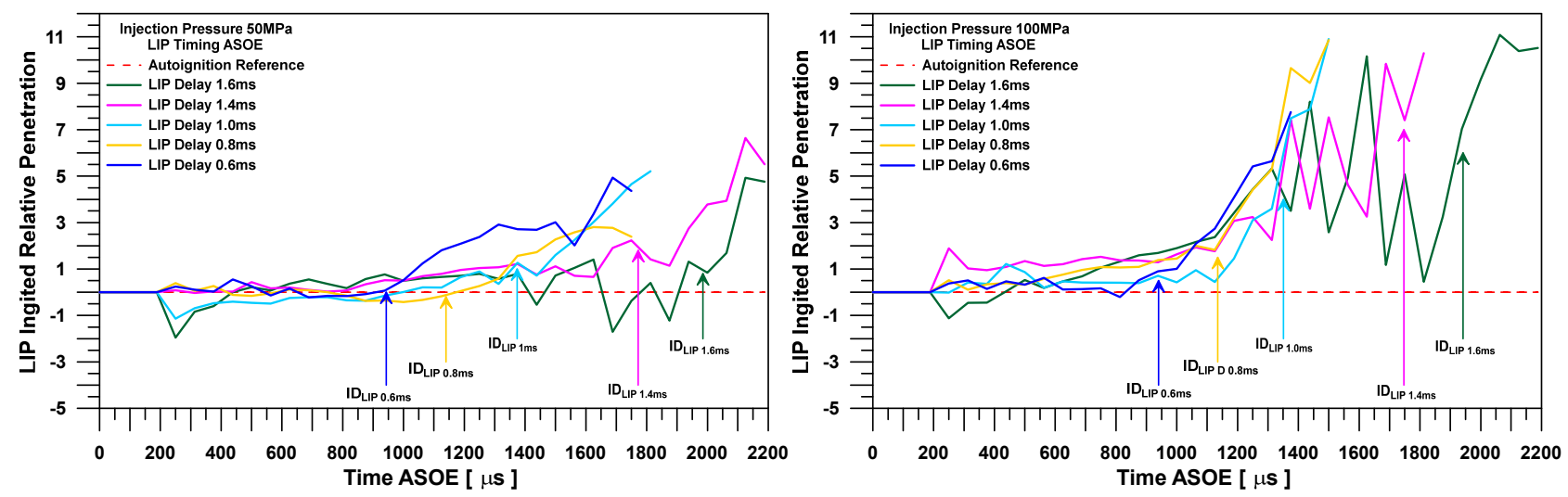

Figure 16 - Relative penetration with respect the autoignition reference (S $\left.S_{l i p}-S_{\text {auto }}\right)$, obtained for the LIP delay variation along the spray axis for both injection pressures of 50MPa and 100MPa. The obtained ignition delay for each test case is also indicated in the graphics.

In addition, results indicate that, despite the very different ignition delay values registered, all the penetration curves accelerated by the flame penetration at different instants could collapse to the same ideal penetration curve. This ideal limit penetration curve should be the theoretical flame penetration curve stated in [31], and so an asymptote limit for the spray penetration velocity. The flame penetration curve is fixed once parameters such as fuel type, injection timing and duration and in-chamber thermodynamic conditions are fixed, and so the differences in ignition delay and combustion development induced by the plasma do not affect the curve itself. It just modifies the celerity with which the penetration curve reaches the flame velocity limit. From the reported penetration curves, it can be seen how the penetration from cases with very different ignition delays, a first acceleration phase occurs, but then the same penetration curve is reached asymptotically. 


\subsection{Laser plasma effect on the soot evolution in the flame}

For cases of conventional autoignition and some of the cases with plasma induced ignition, the registered soot luminosity is found to be generated in the spray tip zone and the penetration after the start of combustion is completely driven by the flame velocity. This fact is clearly shown in Figure 17 as registered images and it implies that, once the combustion has started, the spray penetration should be considered directly a flame penetration in the combustion chamber as the soot luminosity signal always stands at the tip of the spray, as is clearly shown in Figure 18.

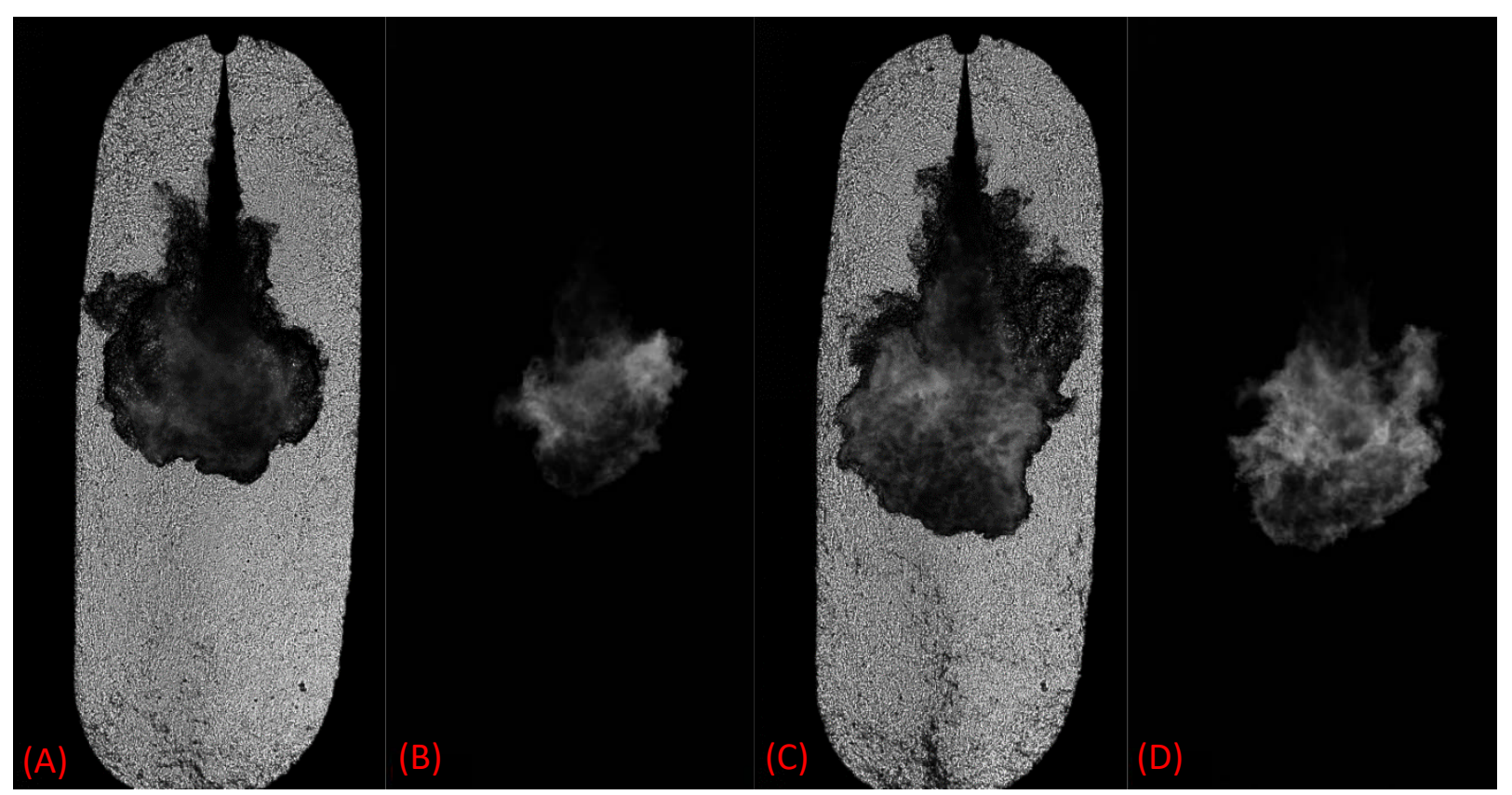

Figure 17 - Examples of good matching between spray tip position determined by the Schlieren imaging (images $A$ and $C$ ) and the Natural Luminosity soot signal acquisition (images $B$ and D). The images are taken from 4 different repetitions $(A$ and $B$ at $1250 \mu s$ ASOE; $($ and $D$ at $1500 \mu$ S ASOE) at 5.3MPa 700K condition, 5OMPa of injection pressure and with the laser ignition at $16 \mathrm{~mm}$ from

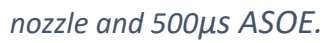

The example reported in Figure 17 is a laser ignition test where the laser is triggered at $16 \mathrm{~mm}$ from the nozzle at $500 \mu$ s ASOE. Two different time instants are shown, namely $1250 \mu$ s for the images $\mathrm{A}$ and $B$ and $1500 \mu$ s for the images $C$ and $D$ The $1250 \mu$ s images are the first registered instant where the soot emission is detectable and it is evident how from that instant onwards the penetration 
could be determined by the natural luminosity images. The results of the image processing carried on these example images is showed in Figure 18.

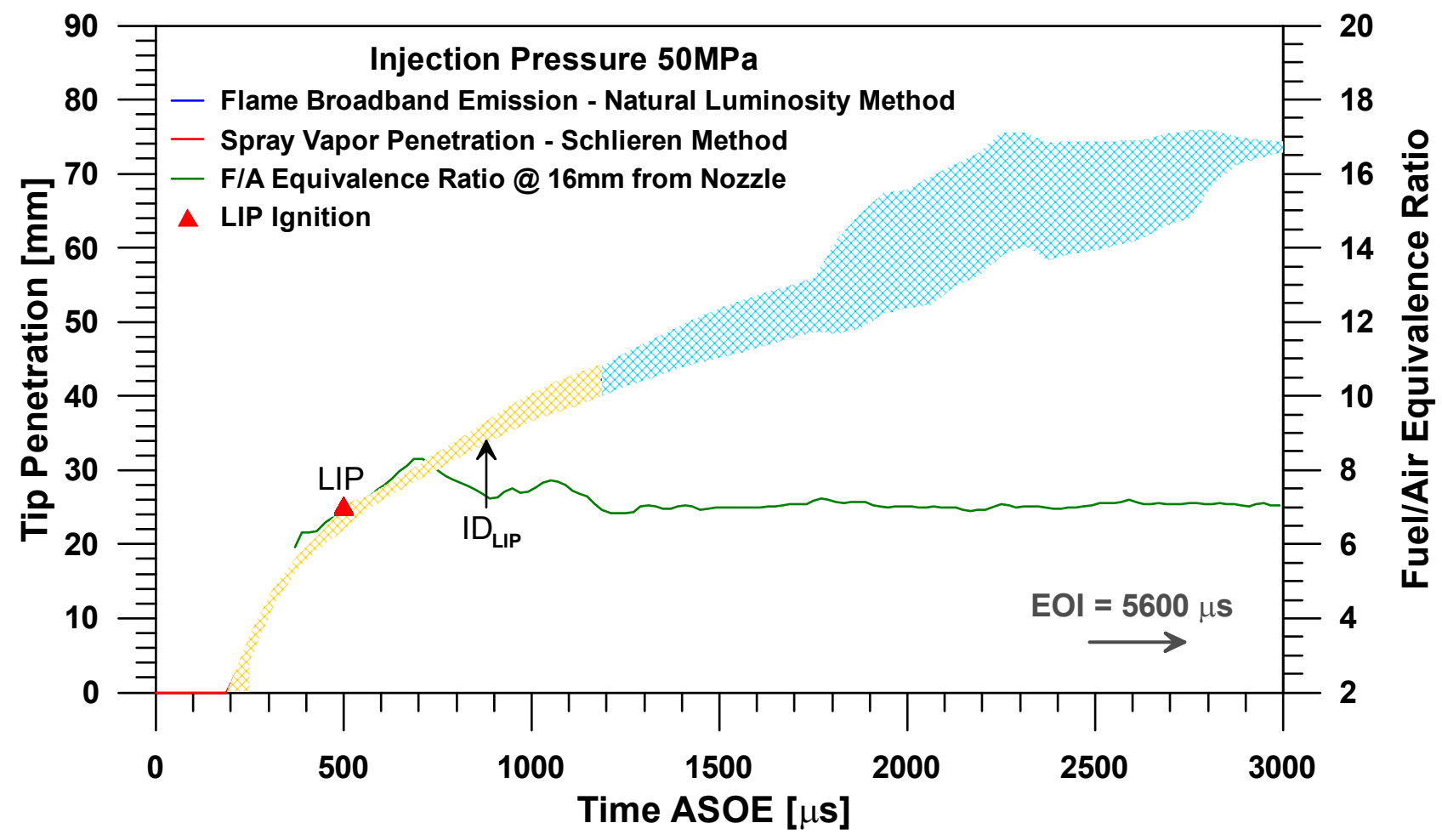

Figure 18 - Vapor Spray Tip penetration curve and Flame Soot Emission penetration curve, obtained respectively from the Schlieren and Natural Luminosity methods. The curves have been obtained from the LIP ignition case provoked at 16mm from the nozzle and $0.5 \mathrm{~ms}$ delay ASOE. The relative fuel/air ratio evolution is also reported as reference as the ignition delay time.

Moving the plasma induction physically along the spray axis or varying the laser pulse timing has shown a shifting effect between the relative position of the spray tip and the soot emission, as can be seen from Figure 19. 


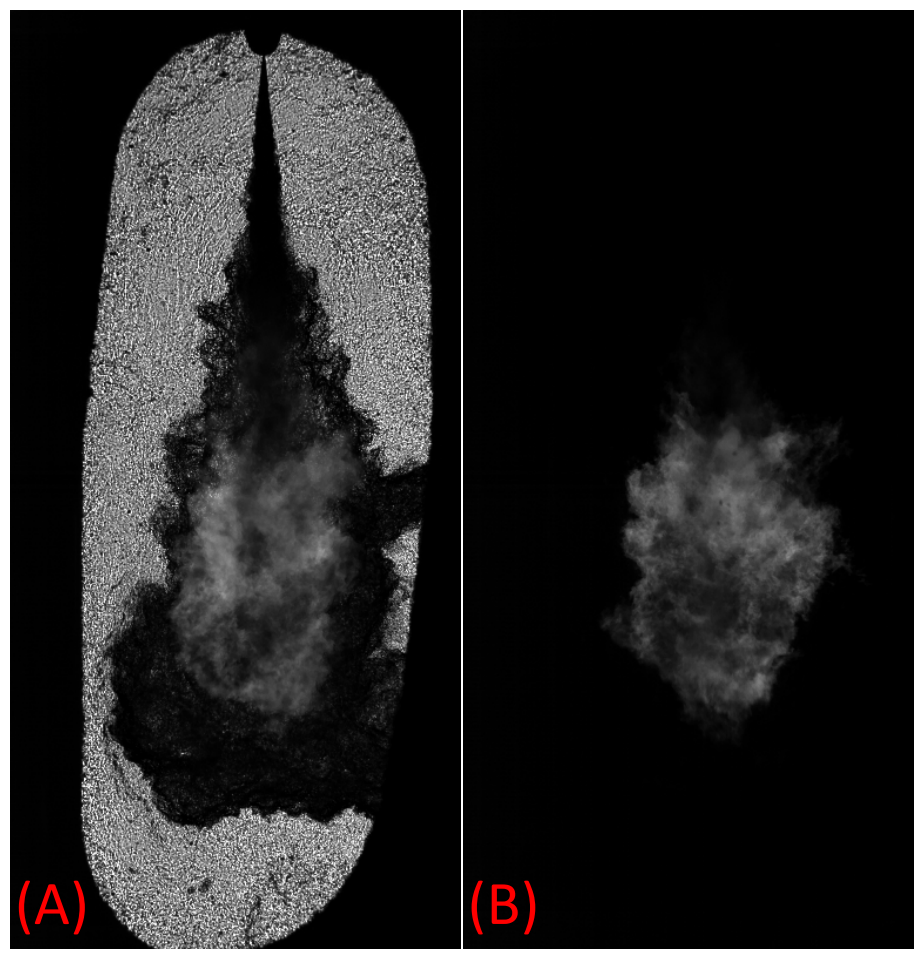

Figure 19 - Example of the observed difference between the spray tip and the soot emission zone for large ignition delay times. Images taken from 2 different repetitions (Schlieren Visualization $(A)$ and Natural Luminosity (B)) at 5.3MPa and 700K for ignition attempts at $16 \mathrm{~mm}$ from nozzle and $1.4 \mathrm{~ms}$ ASOE.

The experimental penetration data analysis has showed that the curves from the two different visualization methods matched well for the shortest laser pulse timing cases but get progressively delayed as the laser pulse timing gets larger, as could be appreciated from Figure 20. 


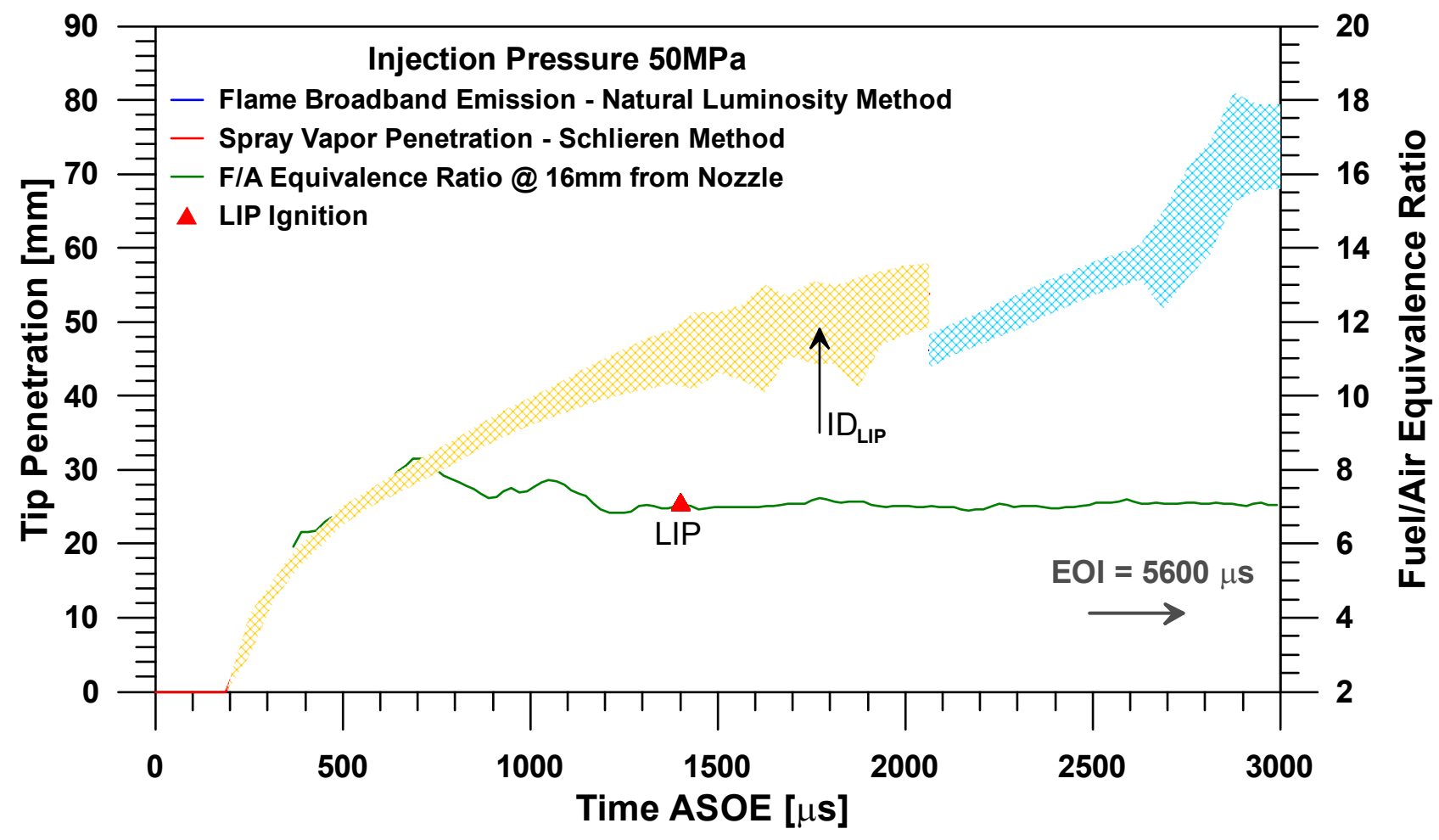

Figure 20 - Vapor Spray Tip penetration curve and Flame Soot Emission penetration curve, obtained respectively from the Schlieren and Natural Luminosity methods. The curves have been obtained from the LIP ignition case provoked at 16mm from the nozzle and 1.4ms delay ASOE. The relative fuel/air ratio evolution is also reported as reference as the ignition delay time.

In fact, in the latest laser pulse timing cases, the curves were clearly unmatched with a substantial difference between the penetration measured with both methods, as shown in Figure 20. This was caused by the fact that the flame was expanding from a region closer to the injector nozzle than the spray tip, as shown in Figure 19. The plasma generation position combined with the ignition delay time contributes to generate a flame kernel not in the "tip zone" of the spray, as typically occurs for the auto-ignition cases, but in an upper region, igniting the mixture nearer to the injector nozzle and so generating a cloud of soot particles that are not reaching the tip of the same spray. 


\section{SUMMARY AND CONCLUSIONS}

A purpose-designed optical system for laser induced plasma ignition has been able to ignite the fuel spray through the upper inflammable limits and reaching the local equivalence ratio of 12 for the $50 \mathrm{MPa}$ injection pressure case. In almost all the tested cases the overall rate of success of ignition in engine like conditions has been almost of the $100 \%$, with the only exception for some misfiring case registered at $11 \mathrm{~mm}$ from the nozzle and characterized by a modeled local equivalence ratio of respectively 12 and 8 for the $50 \mathrm{MPa}$ and $100 \mathrm{MPa}$ injection pressures cases. Such local conditions could represent a transition point between ignitable to non-ignitable equivalence ratios.

The combustion ignition delay variation with the position and timing of the laser plasma induction has shown a clear evolution. Coming closely to the injector nozzle and so moving through richer local equivalence ratios has the effect of retarding the start of combustion with respect the downstream zones. The ignition delay seems to represent a good indicator for forecasting the subsequent combustion development. Some exception to this statement has become evident in the cases of $26 \mathrm{~mm} / 0.8 \mathrm{~ms}$ and $16 \mathrm{~mm} / 0.5 \mathrm{~ms}$, for the $50 \mathrm{MPa}$ injection pressure, and needs a deeper investigation for coming to more solid conclusions.

Each provoked ignition case has registered a higher pressure curves than the autoignition reference. As this fact, theoretically should not appear, because the quantity of fuel injected in each tested case was exactly the same, the only reasonable explanation that could be proposed is to consider the difference in the total unburnt fuel of the different cases, probably higher in the autoignition case. This could be an indicator of how the laser plasma ignition permits a higher efficiency in the total amount of fuel that can be burnt in a combustion event in similar conditions.

The rate of heat release, has shown how with the variation of the ignition delay the premixed combustion indicator peak could completely disappear from the Diesel combustion heat release. 
Moving through shorter delays leads to a more diffusive driven combustion development avoiding the premixed typical first phase.

The analysis of the spray reactive penetration is highly influenced by the internal air flow of the engine test rig that has not allowed a reliable penetration measurement after a certain distance from the injector. For this reason, the results presented and the conclusion reported for this field of combustion diagnostics needs a deeper future investigation. In any case the existence of a flame velocity limit for the reactive penetration in the combustion chamber could be speculated from the recorded penetration curves. It seems that all the different provoked ignition cases present a penetration curve that, even if it gets away from the inert reference after combustion onset, it seems later to accelerate and collapse all asymptotically upon the same curve. Another interesting result obtained from the analysis of the images is the determination of different soot cloud generation locations, linked to the relative position between the spray tip and the laser plasma induction. This fact became evident from the analysis of the mismatching of the averages penetration curves obtained from the application of the two optical techniques. The difference between the soot cloud position and the real spray tip seems to get higher as the plasma spark timing is increased or as it is positioned closest to the injector nozzle.

\section{ACKNOWLEDGMENTS}

The authors acknowledge that this research work has been partly funded by the Government of Spain under the project HiReCo TRA2014-58870-R and grant BES-2015-072119. The equipment used in this work has been partially supported by FEDER project ICTS-2012-06, framed in the operational program of unique scientific and technical infrastructure of the Ministry of Science and Innovation of Spain. 


\section{REFERENCES}

[1] F. Zhao, M.-C. Lai and D. Harrington, "Automotive spark-ignited direct-injection gasoline engines," Progress in Energy and Combustion Science, vol. 25, no. 5, pp. 437-562, October 1999.

[2] M. Lackner and F. Winter, "What is ignition?," IFRF Online Combustion Handbook, vol. Combustion File 256, 2004.

[3] H. Yanagihara, Y. Sato and J. Minuta, "A simultaneous reduction in NOx and soot in diesel engines under a new combustion system (Uniform Bulky Combustion Systems - UNIBUS)," in 17th International Vienna Motor Symposium, 1996.

[4] H. Zhao, $\mathrm{HCCl}$ and CAl Engines for the Automotive Industry, Cambridge,: Woodhead Publishing, 2007.

[5] S. Kimura, S. Aoki, Y. Kitahara and E. Aiyoshizawa, "Ultra-clean Combustion Technology Combining a Low-temperature and Premixed Combustion Concept for Meeting Future Emission Standards," SAE International, 2001.

[6] J. Dale, M. Checkel and P. Smy, "Application of High Energy Ignition Systems to Engines," Prog. Energy Combust. Sci., no. 23, pp. 379-398, 1997.

[7] P. Ronney, "Laser versus conventional ignition of flames," Optical Engineering, no. 33(2), p. 510, 1994.

[8] P. Y. Raizer, "Heating of a gas by a powerful lght pulse," Sov Phys JETP, vol. 17, p. 21:1009, 1965. 
[9] J. Lee and R. Knystautas, "Laser spark ignition of chemical reactive gases," AIAA J, vol. 7, p. 7:312, 1969.

[10] T. Phuoc and F. White, "Laser induced spark ignition of $\mathrm{CH} 4$ /air mixtures," Combustion and Flame, no. 119, pp. 203-216, 1999.

[11] T. X. Phuoc, "Laser spark ignition: Experimental determination of laser-induced breakdown thresholds of combustion gases," Optics Communications, vol. 175, no. 4, pp. 419-423, 2000.

[12] L. Radziemski and D. Cremers, "Laser-Induced Plasmas and Applications," 1989.

[13] H. Kopecek, E. Wintner, R. Pischinger, G. Herdin and J. Klausner, "Basics for a Future Laser Ignition system for Gas Engines," ASME 2000-ICE, Vols. 35-2.

[14] F. Weinberg and J. Wilson, "F.J. Weinberg, J.R. Wilson: “A Preliminary Investigation of the Use of Focused Laser Beams for Minimum Ignition Energy Studies," Proc. Roy. Soc., vol. A, no. 321, pp. 41-52, 1971.

[15] J. Dale, P. Smy and R. Clements, "Laser Ignited Internal Combustion Engine - An Experimental Study," SAE, 1978.

[16] T. X. Phuoc, "Laser-induced spark ignition fundamental and applications," Optics and Lasers in Engineering, vol. 44, no. 5, pp. 351-397, 2006.

[17] L. M. Pickett, A. A. Hoops and J. M. Headrick, "Laser Ignition of multi-injection gasoline sprays," SAE Technical Paper, no. 2011-01-0659, pp. 1-26, 2011.

[18] M. Weinrotter, E. Wintner, K. Iskra, T. Neger, J. Olofsson, H. Seyfried, M. Aldén, M. Lackner, F. Winter, A. Vressner, A. Hultqvist and B. Johansson, "Optical Diagnostics of Laser-Induced 
and Spark Plug-Assisted HCCl Combustion," Homogeneous Charge Compression Ignition (HCCI) Combustion 2005 (SP-1963), 11-14 April 2005.

[19] M. H. Morsy, "Review and recent developments of laser ignition for internal combustion engines applications," Renewable and Sustainable Energy Reviews, no. 16, pp. 4849-4875, 2012.

[20] H. Kopecek, M. Lackner, F. Winter and E. Wintner, "Laser ignition of methane air mixtures at pressures up to 4 MPa," Journal of Laser Physics, no. 13, p. 1365, 2003.

[21] J. V. Pastor, J. M. Garcia-Oliver, A. Garcia and M. Pinotti, "Laser induced plasma methodology for ignition control in direct," Energy Conversion and Management, no. 120, pp. 144-156, 30 April 2016.

[22] V. Bermúdez, J. García, E. Juliá and S. Martínez, "Engine with Optically Accessible Cylinder Head: A Research Tool for Injection and Combustion Processes," 2003.

[23] J. V. Pastor, J. M. Garcia-Oliver, V. Bermudez and C. Micó, "Spray Characterization for Pure Fuel and Binary Blends under Non-Reacting Conditions," 2014.

[24] J. V. Pastor, J. M. Garcia-Oliver, J.-G. Nerva and B. Gimenez, "Fuel effect on the liquid-phase penetration of an evaporating spray under transient diesel-like conditions," Fuel, no. 90, pp. 3369-3381, November 2011.

[25] J. V. Pastor, R. Payri, J. M. Garcia-Oliver and F. J. Briceño, "Schlieren Methodology for the Analysis of Transient Diesel Flame Evolution," SAE Technical Paper, 8 September 2013. 
[26] J. M. Desantes, J. V. Pastor, J. M. García-Oliver and F. J. Briceño, "An experimental analysis on the evolution of the transient tip penetration in reacting Diesel sprays," Combustion and Flame, no. 161, pp. 2137-2150, 2014.

[27] C. Micó Reche, Development of Measurement and Visualization Techniques for Characterization of Mixing and Combustion Process with Surrogate Fuels, Valencia, 2015.

[28] J. V. Pastor, J. J. Lopez, J. M. Garcia and J. M. Pastor, "A 1D model for the description of mixing-controlled inert diesel sprays," Fuel, vol. 87, no. 13-14, p. 2871-2885, October 2008.

[29] J. V. Pastor, J. M. Garcia-Oliver, J. Pastor and W. Vera-Tudela, "One-Dimensional Diesel Spray Modeling of Multicomponent Fuels," Atomization and Sprays, vol. 25, no. 6, pp. 485-517, January 2015.

[30] J. M. Desantes, J. V. Pastor, J. M. Garcia-Oliver and F. J. Briceño, "An experimental analysis on the evolution of the transient tip penetration in reacting Diesel sprays," Combustion and Flame, vol. 161, no. 8, p. 2137-2150, August 2014.

[31] J. V. Pastor, R. Payri, J. M. Garcia-Oliver and F. Briceño, "Schlieren Methodology for the Analysis of Transient Diesel Flame Evolution," pp. 1167-1676, 2013.

[32] M. Lackner, F. Winter, J. Graf, B. Geringer, M. Weinrotter, H. Kopecek, E. Wintner, J. Klausner and G. Herdin, "Laser Ignition in Internal Combustion Engines - A Contribution to a Sustainable Environment".

[33] J. X. Ma, D. R. Alexander and D. E. Poulain, "Laser Spark Ignition and Combustion Characteristics of Methane-Air Mixtures," Combustion And Flame, vol. 112, pp. 492-506, 1998. 
[34] J. L. Beduneau, B. Kim, L. Zimmer and Y. Ikeda, "Measurements of minimum ignition energy in premixed laminar methane/air flow by using laser induced spark," Combustion and Flame, vol. 132, no. 4, pp. 653-665, 2003.

[35] L. M. Pickett, A. A. Hoops and J. M. Headrick, "Laser Ignition of multi-injection gasoline sprays," SAE Technical Paper, no. 2011-01-0659, pp. 1-26, 2011.

[36] D. Bradley, C. Sheppard, I. Suardjaja and R. Woolley, "Fundamentals of High-Energy Spark Ignition with Lasers," Combustion and Flame, no. 138, pp. 33-77, 2004.

[37] G. Weyl, L. Radziemsky and D. Cremers, Phsics of laser-induced breakdown: an update, in Laser-inducted plasma applications, M. Dekker, Ed., New York, 1989, p. 1.

[38] Y. Chen, J. Lewis and C. Parigger, "Spatial and temporal profiles of pulsed laser-induced air plasma emissions," J. Quant. Spectrosc. Radiat. Transfer,, no. 67, pp. 91-103, 2000.

[39] J. Syage, E. Fournier and R. Rianda, "Dynamics of flame propagtion using laser-induced spark initiation: Ignition Energy measurements," Journal of Applied Phisics, no. 64, p. 1499, 1988.

[40] A. J. Torregrosa, P. Olmeda, J. Martin and C. A. Romero, "A Tool for Predicting the Thermal Performance of a Diesel Engine," Heat Transfer Engineering, September 2011. 